\title{
Regulation Mechanism of Graphene Oxide on the Structure and Mechanical Properties of Bio-Based Gel-Spun Lignin/Poly (Vinyl Alcohol) Fibers
}

\section{Yanhong Jin}

Donghua University - Songjiang Campus: Donghua University

\section{Yuanyuan Jing}

Donghua University - Songjiang Campus: Donghua University

\section{Wenxin $\mathrm{Hu}$}

Donghua University - Songjiang Campus: Donghua University

Jiaxian Lin

Donghua University - Songjiang Campus: Donghua University

\section{Yu Cheng}

Donghua University - Songjiang Campus: Donghua University

\section{Xiaona Yang}

Donghua University - Songjiang Campus: Donghua University

\section{Kun Zhang}

Donghua University - Songjiang Campus: Donghua University

Chunhong Lu ( $\nabla$ chlu@dhu.edu.cn )

Donghua University - Songjiang Campus: Donghua University https://orcid.org/0000-0003-4497-191X

\section{Research Article}

\section{Keywords:}

Posted Date: February 12th, 2021

DOI: https://doi.org/10.21203/rs.3.rs-184442/v1

License: (1) (1) This work is licensed under a Creative Commons Attribution 4.0 International License. Read Full License

Version of Record: A version of this preprint was published at Cellulose on April 7th, 2021. See the published version at https://doi.org/10.1007/s10570-021-03859-x. 
1 Regulation mechanism of graphene oxide on the structure

2 and mechanical properties of bio-based gel-spun lignin/poly

3 (vinyl alcohol) fibers

4

Yanhong Jin, Yuanyuan Jing, Wenxin Hu, Jiaxian Lin, Yu Cheng, Xiaona Yang,

\section{Kun Zhang, Chunhong Lu*}

Key Laboratory of Textile Science \& Technology, Ministry of Education, College of Textiles,

Donghua University, Shanghai 201620, China

*Correspondence author’s email: chlu@dhu.edu.cn

Abstract Lignin has been used as a sustainable and eco-friendly filler in composite fibers. However, lignin aggregation occurred at high lignin content, which significantly hindered the further enhancement of fiber performance. The incorporation of graphene oxide (GO) enhanced the mechanical properties of the lignin/poly(vinyl alcohol) (PVA) fibers and affected their structure. With the GO content increasing from 0 to $0.2 \%$, the tensile strength of 5\% lignin/PVA fibers increased from $491 \mathrm{MPa}$ to $631 \mathrm{MPa}$, and Young's modulus increased from 5.91 GPa to $6.61 \mathrm{GPa}$. GO reinforced $30 \%$ lignin/PVA fibers also showed the same trend. The tensile strength increased from $455 \mathrm{MPa}$ to 553 $\mathrm{MPa}$, and Young's modulus increased from 5.39 $\mathrm{GPa}$ to $7 \mathrm{GPa}$. The best mechanical performance was observed in PVA fibers containing 5\% lignin and 0.2\% GO, which had an average tensile strength of $631 \mathrm{MPa}$ and a Young's modulus of $6.61 \mathrm{GPa}$. The toughness values of these fibers are between $9.9-15.6 \mathrm{~J} / \mathrm{g}$, and the fibrillar and ductile fracture microstructure were observed. Structure analysis of fibers showed that GO 
24 reinforced 5\% lignin/PVA fibers had higher crystallinity, and evidence of hydrogen

25 bonding among GO, lignin, and PVA in the gel fibers was revealed. Further, water

26 resistance and swelling behavior of composite PVA fibers were studied to further

27 evidence the structure change of composite fibers.

28 


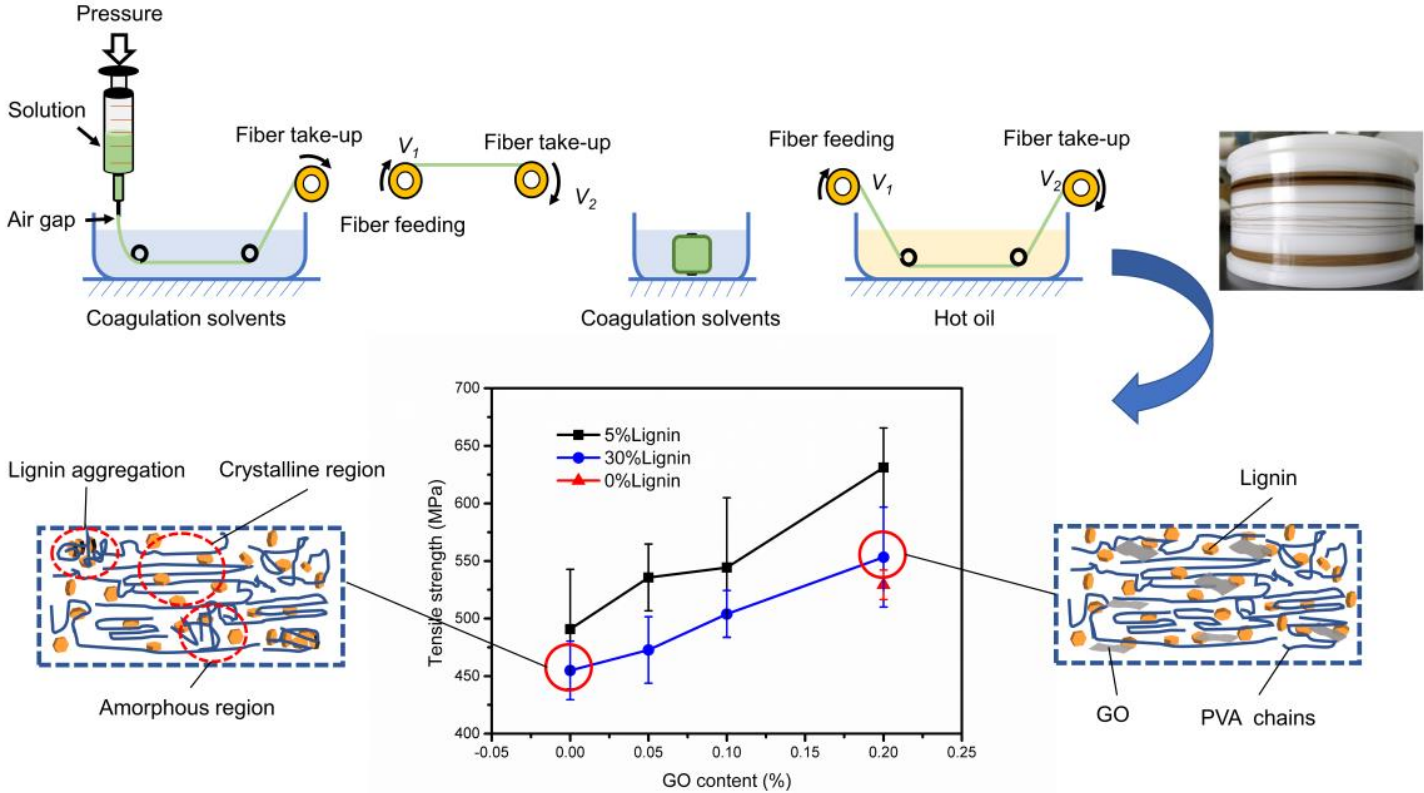

Keywords Gel spinning, Lignin, Graphene oxide, Poly (vinyl alcohol), Fibers, Reinforcement, Mechanism

\section{Introduction}

Poly(vinyl alcohol) (PVA) is a biopolymer with high hydrophilicity and good mechanical properties ( $\mathrm{Lu}$ and Ford 2018), which is widely used as raw material for packaging film, textile sizing, and hydrogel (Iwaseya et al. 2005; Luo et al. 2018), etc.

Similar to polyethylene (PE), the planar zigzag structure of PVA favors fiber-formation and makes it an ideal material for high-performance fibers (Kaufmann and Hesselbarth 2007; Sun et al. 2001). Fiber spinning techniques of PVA (i.e. wet spinning, dry spinning, melt spinning, and gel spinning, etc.) have been well developed in the past few decades (Cha et al. 1994). It is worth mentioning that gel spinning effectively reduces molecular chain entanglement during the spinning process, further promotes the fiber alignment in the drawing process, making it an efficient fabrication method 
for high-performance PVA fibers (Smith and Lemstra 1980). Moreover, filler (i.e. lignin, carbon nanotubes, cellulose whiskers, etc.) reinforcement has been investigated as a promising way for further improvement of fiber properties (Lu et al. 2017a; Uddin et al. 2011; Xu et al. 2010).

Lignin, as the second most abundant biopolymer on earth, is present in all fibrous plants. Nearly 50 million tons of lignin are produced each year as a byproduct of pulp and paper-making industry, while only $2 \%$ is utilized commercially (Laurichesse and Avérous 2014). Due to its high char yield of 50\% (Thakur et al. 2014), lignin has been proposed as a cost-effective and renewable feedstock for carbon fibers (Baker and Rials 2013). However, compared to conventional polyacrylonitrile (PAN)-based carbon fibers, lignin-based carbon fibers have relatively lower mechanical properties (tensile strength of 400-700 MPa, Young's modulus of 40-95 GPa) (Kubo and Kadla 2005; Liu et al. 2015; Sudo and Shimizu 1992). Nevertheless, lignin has the potential to be used as an eco-friendly and sustainable filler in polymer due to its rigid structure. Lignin/PVA fibers have been spun by gel spinning ( $\mathrm{Lu}$ et al. 2017a; Lu et al. 2017b). With the incorporation of 5\% lignin, PVA fiber exhibited a tensile strength of $1.1 \mathrm{GPa}$ and a Young's modulus of $36 \mathrm{GPa}$. Even at up to $50 \%$ lignin, lignin/PVA fibers had better mechanical properties than that of neat PVA fibers spun under optimum conditions ( $\mathrm{Lu}$ et al. 2017a). As hydrogen bonding occurred between lignin and PVA hydroxyl groups, the molecular mobility of PVA enhanced, and fiber draw ratios increased. However, at lignin content of more than $20 \%$, filler aggregation and poor alignment of lignin along the fiber axis were observed, which impeded the fabrication of even stronger lignin 
reinforced PVA fibers (Lu et al. 2017a). To ultimately achieve high-performance ligninbased fibers, the intermolecular compatibility between lignin and PVA, as well as the molecular alignment in fiber structure should be further optimized.

Graphene is a two-dimensional carbon material with exceptional inherent mechanical properties, including extremely high tensile strength of $125 \mathrm{GPa}$ and Young's modulus of $1000 \mathrm{GPa}$ (Lee et al. 2008; Zhu et al. 2010). However, the weak interfacial interaction between the graphene nanofillers and the polymer matrix hinders the preparation of a homogeneous dispersion and further fibers with excellent mechanical performance. Graphene oxide (GO), with oxygen-containing groups (i.e. hydroxyl, carbonyl, carboxyl, and glycidyl groups) on the surface of nanosheets, has attracted considerable attention as filler for polymeric composites (Rourke et al. 2011; Wilson et al. 2009) due to its low cost, good mechanical performance and excellent compatibility with polymers (Liang et al. 2009). For instance, GO/PVA nanocomposite hydrogels with aligned hierarchical microstructure and anisotropic mechanical properties had been reported (Luo et al. 2018). Gel-spun GO/PVA nanocomposite fibers with GO nanosheets highly oriented along the fiber axis were also prepared ( $\mathrm{Hu}$ et al. 2017). The tensile strength increased $46.15 \%$ after only $0.5 \mathrm{wt} \%$ GO nanosheets were incorporated into fibers. Although $\mathrm{Hu}$ et al. prepared GO/lignin/PVA films, the tensile strength of 100-125 $\mathrm{MPa}$ is far below the standards of industrial high-performance applications (Hu et al. 2019). Therefore, insufficient studies employ GO as filler in lignin/PVA gel-spun fibers to overcome the structural impediments of lignin/PVA fibers at high lignin contents for further enhancement in fiber performance or investigate the 
synergistic effects of GO and lignin on the mechanical properties and structure of PVA fibers.

To better address the regulation mechanism of GO on the structure and mechanical properties of bio-based gel-spun lignin/PVA fibers, lignin/PVA, GO/PVA and GO/lignin/PVA composite fibers with varying lignin and GO contents utilizing gelspinning technique were fabricated in this work. The prepared fibers were characterized structurally by scanning electron microscopy (SEM), X-ray diffraction analysis (XRD), and Fourier transform infrared spectroscopy (FTIR). Mechanical performance, water resistance, and swelling ratios were also evaluated, and the effects of lignin and GO on the fiber structure were discussed. This study will possibly expand the application of low-cost bio-based high-performance fibers in industry.

\section{Experimental section}

Materials

PVA $\left(\mathrm{M}_{\mathrm{w}}=146,000-186,000,99 \%\right.$ hydrolysis, Sigma-Aldrich Co., USA $)$ and graphene oxide aqueous dispersion (GO, concentration of $10 \mathrm{mg} / \mathrm{mL}$, sheets diameter of 5-8 $\mu \mathrm{m}$, Hangzhou Gaoxi Technology Co., Ltd., China) were used as received. Lignin (purity of 90\%, Hubei Yunmei Technology Co., Ltd., China) was used after purification. Dimethyl sulfoxide (DMSO, Sigma-Aldrich Co., USA), acetone, and methanol (Shanghai Titan Technology, Inc., China) were used as received. All water used was deionized. 
Preparation of spinning dopes

To remove low-molecular-weight fractions, lignin was first dissolved in acetone and then purified by vacuum filtration. Later, it was washed by deionized (DI) water for multiple times and dried in a vacuum oven at $65{ }^{\circ} \mathrm{C}$ for $4 \mathrm{~h}$. Finally, lignin was ground into fine powder by the mortar and pestle.

Three types of solution mixtures (GO/PVA, lignin/PVA, and GO/lignin/PVA) were prepared for spinning. To prepare GO/PVA solution, GO (at weight ratios of $0.2 \%(\mathrm{w} / \mathrm{w})$ GO to polymer) and PVA powder (10 g) were dissolved in $100 \mathrm{~mL}$ of $80 / 20(\mathrm{v} / \mathrm{v})$ $\mathrm{DMSO} / \mathrm{DI}$ water under constant stirring at $85^{\circ} \mathrm{C}$ for $2 \mathrm{~h}$. For the lignin/PVA solutions, PVA powder (10 g) and lignin, at weight ratios of 5\% and 30\% (w/w) lignin to polymer, were dissolved in $100 \mathrm{~mL}$ of 80/20 (v/v) DMSO/DI water under constant stirring at $85{ }^{\circ} \mathrm{C}$ for $2 \mathrm{~h}$, respectively. To prepare GO/lignin/PVA dopes, at weight ratios of $5 \%$ and $30 \%(\mathrm{w} / \mathrm{w})$ lignin to polymer, concentrations of $0.05 \%, 0.1 \%$ and $0.2 \%(\mathrm{w} / \mathrm{w}) \mathrm{GO}$ to polymer were also dissolved in $80 / 20(\mathrm{v} / \mathrm{v}) \mathrm{DMSO} / \mathrm{DI}$ water at the same condition, respectively. All prepared solutions were maintained at $65^{\circ} \mathrm{C}$ before spinning.

Gel spinning

The gel spinning process is illustrated in four steps (Fig. 1). Steps 1 involves the loading of polymer dope $(50 \mathrm{~mL})$ into a syringe maintained at $60^{\circ} \mathrm{C}$ and the extrusion of the polymeric jet through a $0.72 \mathrm{~mm}$ inner diameter syringe needle. Lignin/PVA and GO/lignin/PVA polymeric jets were injected into acetone/methanol $(85 / 15 \mathrm{v} / \mathrm{v})$ coagulation solvents maintained at $-25{ }^{\circ} \mathrm{C}$ with an air gap of $3-5 \mathrm{~mm}$ due to that 
methanol could facilitate PVA gel fiber formation but partially dissolve lignin while acetone could effectively hinder the lignin diffusion from fiber structure into coagulation solvents (Lu et al. 2017a). GO/PVA fibers were spun into 100\% methanol coagulation solvent for good fiber formation under the same spinning condition. All asspun fibers which underwent $1 \mathrm{~m}$ length coagulation bath were later collected onto a rotating take-up winder. The collected as-spun fibers were air drawn at room temperature (Step 2) before storage in coagulation solvents with the same compositions as the ones in Step 1 for gel aging at $5{ }^{\circ} \mathrm{C}$ for $24 \mathrm{~h}$ (Step 3). Step 4 involves the hot drawing of fibers through silicone oil bath for four stages at high temperature $\left(100-220^{\circ} \mathrm{C}\right)$. The draw ratio $(D R)$ of each drawing stage was calculated by Equation (1):

$D R=\frac{V_{2}}{V_{1}}$

where $V_{l}$ represents the velocity of the fiber feeding winder and $V_{2}$ represents the velocity of the fiber take-up winder, respectively (Fig. 1, Step 2 \& 4). Drawing parameters for gel-spun fibers are listed in Table 1, which will be discussed later.

(a)

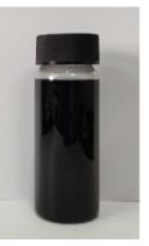

(e) Pressure (b)

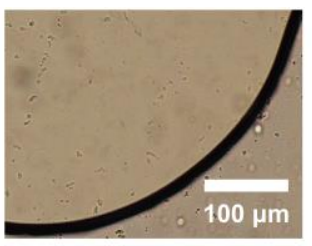

(c)

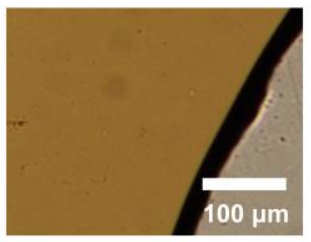

(d)

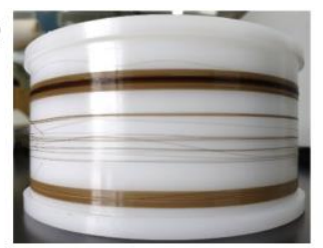

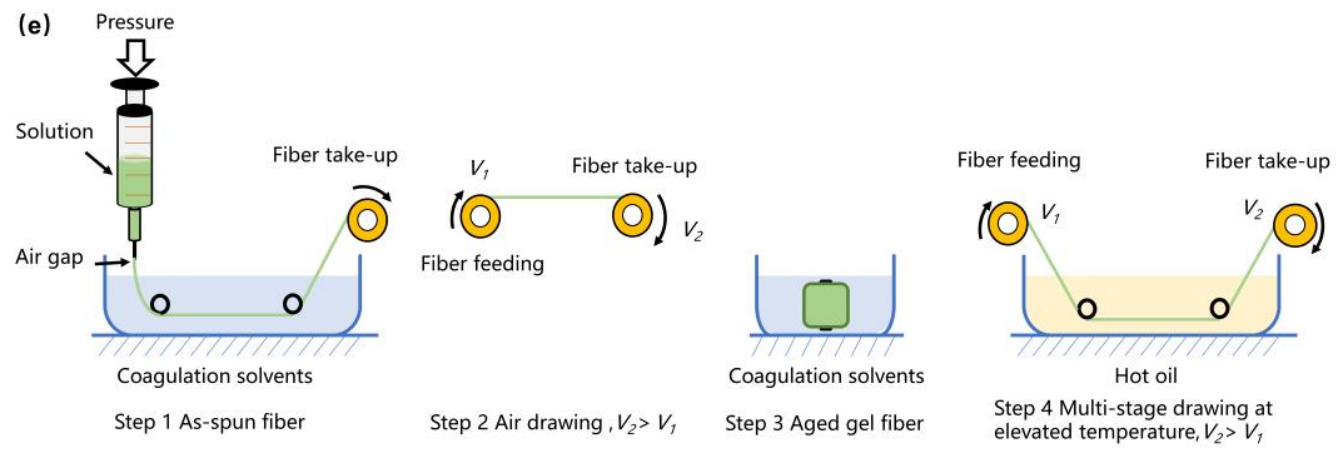

Fig. 1 Homogeneity of GO/lignin/PVA dopes: (a) digital photograph of $0.2 \% \mathrm{GO} / 30 \%$ 
lignin/PVA solution, and optical micrographs of (b) $0.2 \% \mathrm{GO} / 5 \%$ lignin/PVA and (c) $0.2 \% \mathrm{GO} / 30 \%$ lignin/PVA spinning solutions; (d) digital photograph of $30 \%$ lignin/PVA drawn fibers prepared by gel spinning, (e) the fiber gel spinning process: as-spun gel fiber formation (Step 1), air drawing (Step 2), gel fiber aging (Step 3), and multiple-stage fiber drawing (Step 4)

Mechanical testing

The mechanical properties of fibers were measured with the XQ-1C tensile testing system according to ASTM D3379. Mechanical testing was performed with a $20 \mathrm{~mm}$ gauge length, a strain rate of $15 \mathrm{~mm} / \mathrm{min}$, and a sample size of 10 . Values of fiber crosssectional area $A$ were determined gravimetrically from measurements of linear density, $d$, and the density of the composite fiber $\rho$, using Equation (2):

$A=d / \rho$

where $d$ values were obtained by weighing the mass of $30 \mathrm{~cm}$ composite fibers. Before weighing, the fibers were rinsed by isopropyl alcohol to remove residual silicone oil on the fiber surface and dried at room temperature for $24 \mathrm{~h}$. Values of $\rho$ were calculated by Equation (3):

$$
\rho=\rho_{P V A} w_{P V A}+\rho_{\text {lignin }} w_{\text {lignin }}+\rho_{G O} w_{G O}
$$

where $w$ is the weight fraction of PVA, lignin, and GO, respectively. The density of both PVA (Luo et al. 2013) and lignin (Hu 2002) is $1.3 \mathrm{~g} / \mathrm{cm}^{3}$, and the density of GO is 2.2 $\mathrm{g} / \mathrm{cm}^{3}$ (Hu et al. 2017). The weight fraction of GO $(0.05 \%, 0.1 \%$, or $0.2 \%)$ was so small that it could be negligible. Therefore, the density of each composite fiber was 
approximately $\rho=1.3 \mathrm{~g} / \mathrm{cm}^{3}$.

Tensile toughness $\left(U_{t}\right)$ was calculated from the integration of the stress-strain curve of each composite fiber. It represents the energy absorbed during the fiber breakage process (Song et al. 2013), which can be expressed by Equation (4):

$$
U_{t}=\int \sigma_{i} \varepsilon_{i}
$$

where $\sigma_{i}$ and $\varepsilon_{i}$ are the stress and strain at each data point $i$, respectively.

\section{Imaging analysis}

A SU8010 scanning electron microscopy was used to study the morphology of the fiber facture tips after mechanical testing. Fractured fiber samples were sputter coated with gold and imaged by SEM at $5 \mathrm{kV}$ accelerating voltage.

\section{Fiber structural analysis}

X-ray Diffraction patterns of fibers were collected by Rigaku D/max-2550 PC Xray Diffractometer using $\mathrm{Cu} \mathrm{K} \alpha$ radiation $(\lambda=1.541 \AA)$ at voltage of $40 \mathrm{kV}$ and operating current of $150 \mathrm{~mA}$. Shredded fibers were scanned at a step size of $0.05^{\circ}$ with $2 \theta$ between $5^{\circ}$ and $60^{\circ}$.

Peak fitting was performed by MDI Jade 6 software. The percent crystallinity $\left(X_{c}\right)$ of each composite fiber was calculated based on crystalline $\left(A_{c}\right)$ and amorphous $\left(A_{a}\right)$ peak areas (Minus et al. 2006):

$X_{c}(\%)=\left(\frac{A_{c}}{A_{c}+A_{a}}\right) \times 100 \%$

Aligned fiber bundles of more than 100 fibers with $3 \mathrm{~cm}$ in length were placed on 
the sample holder and scanned for molecular anisotropy. $\mathrm{Cu} \mathrm{K}_{\alpha}$ radiation $(\lambda=1.541 \AA)$ at voltage of $40 \mathrm{kV}$ and operating current of $150 \mathrm{~mA}$ were applied. Fibers were scanned in the equator and meridian directions at a step size of $0.05^{\circ}$ with $2 \theta$ between $5^{\circ}$ and $60^{\circ}$. Then the detector was fixed at the $2 \theta$ position of the strongest peak, and the sample holder rotated from $-90^{\circ}$ to $270^{\circ}$ along the azimuth angle to test the intensity distribution of the diffraction peak. Peak fitting was performed by MDI Jade 6 software. The orientation (y) is calculated by Equation (6) (Zhu et al. 2009):

$y(\%)=\frac{360-\sum H_{i}}{360} \times 100 \%$

where $H_{i}$ is the half-height width at peak $i$.

The structural analysis of fibers was performed for 128 scans at $4 \mathrm{~cm}^{-1}$ spectral resolution on the NEXUS-670 Fourier transform infrared spectrophotometer equipped with attenuated total reflection.

FTIR spectra in the $800-4200 \mathrm{~cm}^{-1}$ range were normalized to the $854 \mathrm{~cm}^{-1}$ band (C-C stretching) (Peppas 1977; Tretinnikov and Zagorskaya 2012). The C-C stretching peak is chosen as a reference due to that its absorbance is not significantly affected by processing. Percent crystallinity $\left(X_{c}\right)$ of polymer is expressed in Equation (7):

$X_{c}=\left(a+b \frac{A_{1114}}{A_{854}}\right) \times 100 \%$ where $a=14.40$ and $b=24.09$ are constants whose values are calculated from known values of percent crystallinity from X-ray diffraction patterns (Fig. S1, S2 and Table S1 in Supplementary Information, SI). Absorbance values for $A_{1144}$ and $A_{854}$ were calculated from infrared spectra. 
Water dissolution and swelling

To investigate the water resistance of PVA fibers with different lignin and GO contents, fiber bundles $(2 \mathrm{mg})$ designated as (lignin to PVA)/(GO to PVA) ratios of $0 / 0.01,0 / 0.02,5 / 0,5 / 0.05,5 / 0.1,5 / 0.2,30 / 0,30 / 0.05,30 / 0.1$, and 30/0.2, were placed in $25 \mathrm{~mL}$ of water and gradually heated from 25 to $85^{\circ} \mathrm{C}$. Optical images of fibers were obtained by optical microscope (ECLIPES LV100N POL) after water immersion of fibers. To study the swelling behavior of GO/lignin/PVA fibers, fiber bundles were immersed in DI water for $24 \mathrm{~h}$ at room temperature. Post immersion, the fibers were blotted with filter paper to remove excess water before being weighed. The fiber swelling ratio $(S)$ was calculated according to Equation (8):

$S=\frac{m_{w}-m_{d}}{m_{d}} \times 100 \%$

where $m_{d}$ and $m_{w}$ represent the mass of the fiber before and after wetting, respectively.

\section{Results and discussion}

Effect of GO on lignin/PVA fiber drawing process

In this section, the drawing parameters for all gel-spun composite fibers, including drawing ratios, drawing temperature, effective diameters, and linear density, were summarized in Table 1. Changes in drawing temperature and drawing ratios of each stage were observed.

As the first drawing process after the as-spun fibers being collected from the coagulation bath, air drawing facilitates the alignment of molecular chains, the 
230 gel aging process (Zhang et al. 2011). With the air drawing process applied, the

231 subsequent thermal drawing of gel-spun fibers is more stable, which may contribute to

232 the enhanced strength, toughness, and dimensional stability of the gel-spun fibers,

233 which will be further evidenced in the later section.

235 Table 1. Drawing parameters for gel-spun lignin/PVA, GO/PVA, and GO/lignin/PVA 236 fibers

\begin{tabular}{|c|c|c|c|c|c|c|c|c|c|c|}
\hline \multirow{2}{*}{$\begin{array}{c}\text { Lignin } \\
\text { content } \\
\text { GO } \\
\text { content }\end{array}$} & & \multirow{2}{*}{$\begin{array}{c}0 \\
0.2 \%\end{array}$} & \multicolumn{4}{|c|}{$5 \%$} & \multicolumn{4}{|c|}{$30 \%$} \\
\hline & & & 0 & $0.05 \%$ & $0.1 \%$ & $0.2 \%$ & 0 & $0.05 \%$ & $0.1 \%$ & $0.2 \%$ \\
\hline As-spun & $D R$ & 1.9 & 1.8 & 1.9 & 1.8 & 1.8 & 1.8 & 1.7 & 1.8 & 2.1 \\
\hline $\begin{array}{c}\text { Air } \\
\text { drawing }\end{array}$ & $D R$ & 2.5 & 2.3 & 2.5 & 2.5 & 2 & 2.3 & 2 & 2.5 & 1.8 \\
\hline Stage 1 & $\mathrm{~T} /{ }^{\circ} \mathrm{C}$ & 105 & 110 & 120 & 105 & 105 & 125 & 115 & 110 & 110 \\
\hline drawing & $D R$ & 1.2 & 1.5 & 1.6 & 1.5 & 1.8 & 1.5 & 2.2 & 1.8 & 1.7 \\
\hline Stage 2 & $\mathrm{~T} /{ }^{\circ} \mathrm{C}$ & 180 & 180 & 180 & 180 & 180 & 180 & 190 & 180 & 180 \\
\hline drawing & $D R$ & 2 & 1.5 & 1.4 & 1.2 & 1.3 & 1.5 & 1.2 & 1.3 & 1.2 \\
\hline Stage 3 & $\mathrm{~T} /{ }^{\circ} \mathrm{C}$ & 200 & 200 & 205 & 200 & 200 & 200 & 200 & 200 & 200 \\
\hline drawing & $D R$ & 1.3 & 1.1 & 1.1 & 1.1 & 1.2 & 1.1 & 1.2 & 1.1 & 1.2 \\
\hline Stage 4 & $\mathrm{~T} /{ }^{\circ} \mathrm{C}$ & 225 & 220 & 220 & 220 & 220 & 215 & 215 & 220 & 220 \\
\hline drawing & $D R$ & 1.1 & 1.1 & 1.1 & 1.1 & 1.1 & 1.1 & 1.1 & 1.1 & 1.1 \\
\hline Total $D R^{\mathrm{a}}$ & & 16.3 & 11.3 & 12.9 & 9.8 & 11.1 & 11.3 & 11.8 & 12.7 & 10.2 \\
\hline $\begin{array}{l}\text { Effective } \\
\text { diameter } \\
\qquad / \mu \mathrm{m}\end{array}$ & & 50 & 58 & 54 & 62 & 49 & 64 & 54 & 59 & 55 \\
\hline $\begin{array}{l}\text { Linear } \\
\text { density } \\
d / \text { dtex }\end{array}$ & & 26 & 34 & 30 & 39 & 25 & 41 & 30 & 36 & 31 \\
\hline
\end{tabular}

237 a Total $D R$ is the cumulative draw ratio from as-spun drawing, air drawing, and hot 238 drawing. 
After gel aging of the air-drawn fibers in the coagulation solvents for $24 \mathrm{~h}$, gel fibers were further drawn in hot oil for multiple stages at elevated temperatures. In the

first stage, the drawing temperature of fibers is between $105-120^{\circ} \mathrm{C}$. It was observed that solvent diffused from the fibers into the high-temperature oil during the first stage

of thermal drawing, which facilitate the conversion of gel fibers into solid fibers. The temperature was increased to $180-190{ }^{\circ} \mathrm{C}$ in the second stage of thermal drawing. There was still slight solvent diffusion during this stage, which was attributed to the residual DMSO (with a boiling point of $189^{\circ} \mathrm{C}$ ) in the fibers. In the third and fourth stages, the fibers were further drawn to obtain finer structure at increased drawing temperature. Effective diameters and linear density of fibers are shown in Table 1. Changes of GO/lignin/PVA fibers in stage drawing ratios were slight. The draw ratio of $0.2 \% \mathrm{GO} / \mathrm{PVA}$ fiber could reach 16.3 , while the total draw ratios of GO/lignin/PVA fibers were in the range of 9.8-12.9 regardless of the content of lignin. It is possible that the intermolecular interaction in the GO/lignin/PVA ternary system, which will be shown in the later section, impeded the enhancement of fiber draw ratios.

Effect of GO content on lignin/PVA fiber mechanical properties

The effect of GO content on the tensile strength and Young's modulus of gel-spun lignin/PVA fibers is discussed in this section. Generally speaking, fibers with 5\% lignin have significantly better mechanical properties than those with $30 \%$ lignin content, which is attributed to the higher crystallinity (as shown in Table 2), the stronger hydrogen bonding between lignin and PVA, and the better molecular orientation of 5\% 

lignin fillers exhibited superior mechanical properties compared to those containing only lignin fillers (Fig. 2). As the GO content increased from 0 to $0.2 \%$, the tensile strength of $5 \%$ lignin/PVA fibers increased from $491 \mathrm{MPa}$ to $631 \mathrm{MPa}$, and Young's modulus increased from 5.91 GPa to $6.61 \mathrm{GPa}$. The 30\% lignin/PVA fibers showed the same trend as the GO content increased from 0 to $0.2 \%$ : the tensile strength increased from $455 \mathrm{MPa}$ to $553 \mathrm{MPa}$, and Young's modulus increased from $5.39 \mathrm{GPa}$ to $7 \mathrm{GPa}$. The maximum tensile strength was $631 \mathrm{MPa}$ at $0.2 \% \mathrm{GO} / 5 \%$ lignin, and the maximum modulus was $7 \mathrm{GPa}$ at $0.2 \% \mathrm{GO} / 30 \%$ lignin.

(a)

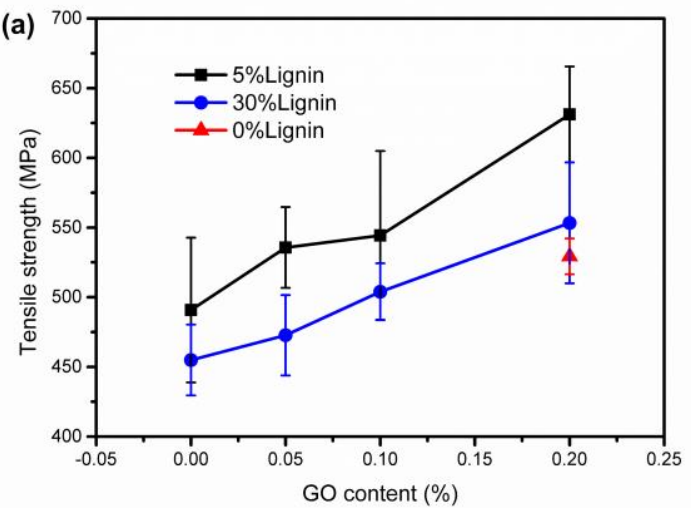

(b)

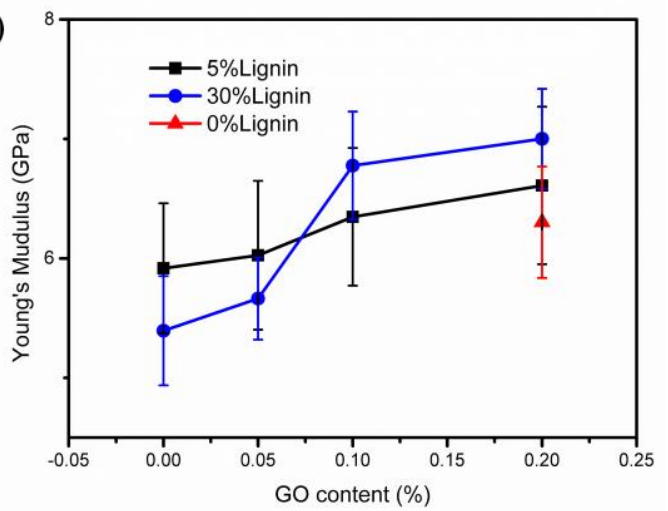

270

Fig. 2 Tensile strength and Young's modulus of gel-spun PVA fibers of 0/5/30\% lignin and $0 / 0.05 \% / 0.1 \% / 0.2 \% \mathrm{GO}$

It was clearly shown that for GO/lignin/PVA composite fibers, both 5\% and 30\% lignin/PVA fibers had the best mechanical properties at $0.2 \% \mathrm{GO}$. To better verify the role of lignin in the ternary system of composite fibers, $0.2 \% \mathrm{GO} / \mathrm{PVA}$ fibers were fabricated and tested for comparison. Fig. 2 showed that the tensile strength (529 MPa) and Young's modulus $(6.3 \mathrm{GPa})$ of $0.2 \% \mathrm{GO} / \mathrm{PVA}$ fiber were lower than those of $0.2 \%$ 

281 of fiber properties. GO

GO/lignin/PVA fiber, confirming that lignin may work as an efficient filler in GO/PVA fibers and that the synergistic effect of GO, lignin and PVA results in the enhancement

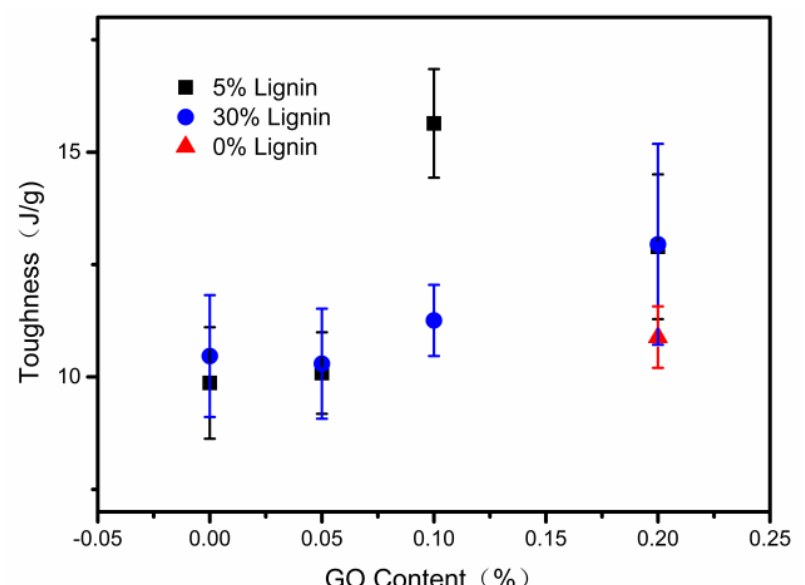

Fig. 3 Toughness of gel-spun PVA fibers with 0/5/30\% lignin and 0/0.05\%/0.1\%/0.2\%

The effect of GO content on gel-spun lignin/PVA fiber toughness is shown in Fig.

3. Toughness indicates fiber's ability to absorb mechanical energy before rupture (Shin et al. 2012). The strain at break values for all of the lignin/PVA and GO/lignin/PVA fibers ranged between $5.5 \%$ and $7.5 \%$ regardless of the filler content. Toughness values of GO/lignin/PVA fibers with varying GO and lignin contents ranged from 9.9 to 15.6 $\mathrm{J} / \mathrm{g}$, which were much greater than that of reported GO/PVA composites fiber (6 $\mathrm{J} / \mathrm{g}$ )(Shin et al. 2012). A maximum toughness value of $15.6 \mathrm{~J} / \mathrm{g}$ was observed in $0.1 \%$ $\mathrm{GO} / 5 \%$ lignin/PVA fibers. As the GO content increased, the toughness of both $5 \%$ and $30 \%$ lignin/PVA fibers slightly increased. Compared with $0.2 \% \mathrm{GO} / 5 \%$ and 30\%lignin/PVA composite fibers, $0.2 \% \mathrm{GO} / \mathrm{PVA}$ fiber had a lower toughness value $(10.88 \mathrm{~J} / \mathrm{g})$. This indicates that lignin with a large amount of rigid structure can more 
effectively increase the fiber toughness than GO.

298

Effect of GO content on lignin/PVA fiber structure

Fiber fracture tips from mechanical testing were imaged by SEM, as shown in Fig. 4. It was observed that all fibers had a dense structure without pores. Fiber diameters were in the range of 50-65 $\mu \mathrm{m}$, which were consistent with the effective diameters calculated in Table 1 . The fibrillar structure of the $0.2 \%$ GO/PVA fiber was also observed (Fig. S3 in SI). The addition of GO could effectively enhance the strength of the PVA fiber (Hu et al. 2017) and the fibrillar structure indicated the highly aligned polymer chains along the fiber axis. 5\% lignin/PVA fiber showed a smooth fracture tip (Fig. 4a). With $0.2 \%$ GO incorporated, $0.2 \% \mathrm{GO} / 5 \%$ lignin/PVA fiber exhibited more fibrillar microstructure and more ductile fracture tip (Fig. 4b). PVA fibrils are related to the highly oriented and ordered polymer chains, which are responsible for the good mechanical properties (tensile strength of $631 \mathrm{MPa}$, Young's modulus of $6.61 \mathrm{GPa}$ ). The fibrillar structure was observed in 30\% lignin/PVA fiber (Fig. 4c), which was possibly due to the plasticizing effect of lignin ( $\mathrm{Lu}$ et al. 2017a). The fibrillar structure was also observed in $0.2 \% \mathrm{GO} / 30 \%$ lignin/PVA fiber (Fig. 4d). Even in high-resolution images, no aggregation of lignin or GO was observed in the $0.2 \% \mathrm{GO} / 30 \%$ lignin/PVA fiber, which only demonstrated uniform structure without obvious defects. In summary, both lignin and GO promoted the formation of PVA fibrillar structure and were responsible for the enhancement of mechanical properties aforementioned. 

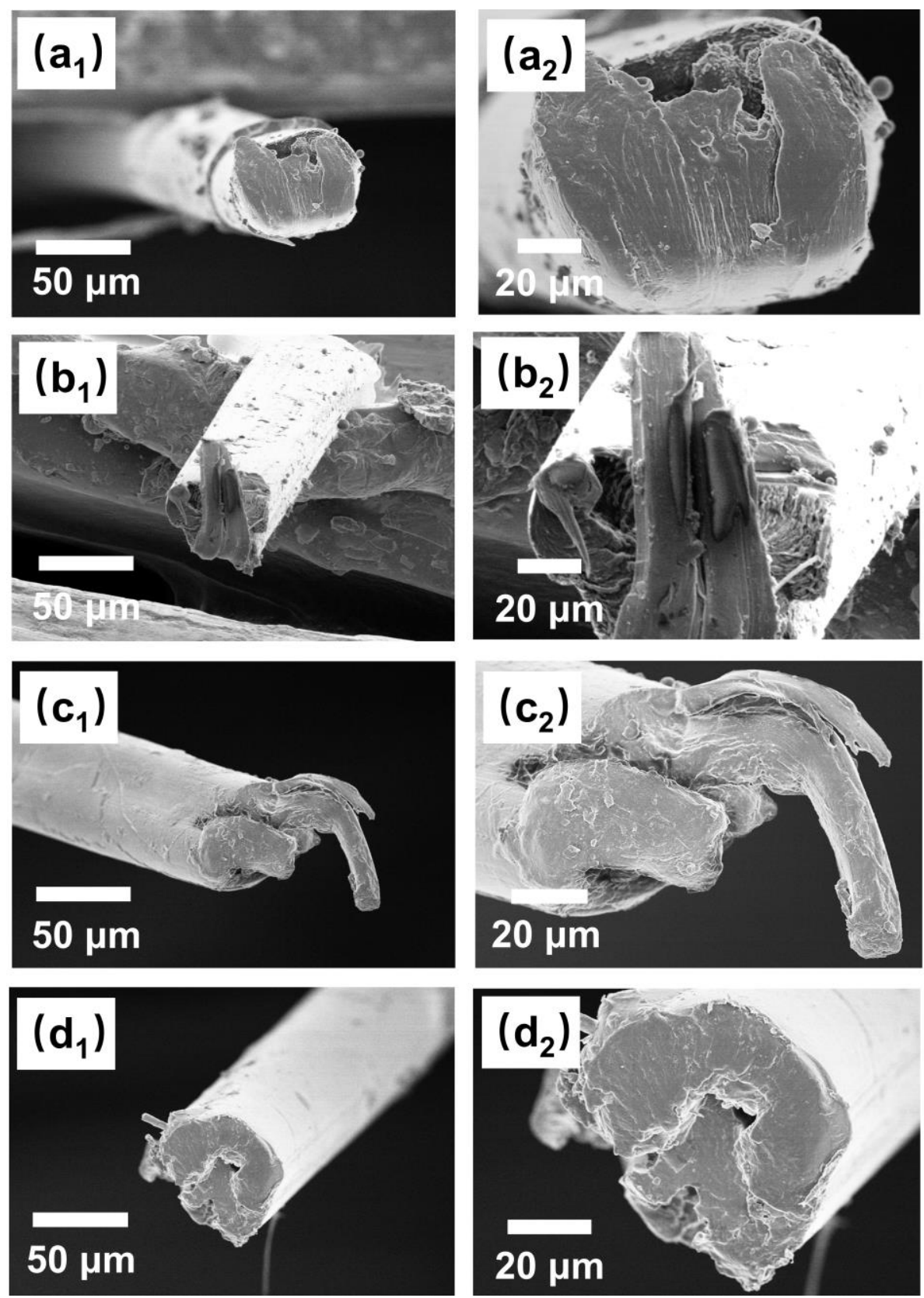

Fig. 4 (1) Low- and (2) high-resolution SEM images of fracture tips of (a) 5\% lignin

319 /PVA fibers, (b) $0.2 \% \mathrm{GO} / 5 \%$ lignin/PVA fibers, (c) $30 \%$ lignin/PVA fibers, (d) $0.2 \%$

GO/30\% lignin/PVA fibers

To better understand the effect of GO filler on the mechanical properties of

323 lignin/PVA fibers, fiber crystallinity, and molecular alignment will be discussed in this section. Both molecular adhesion and orientation of polymer chains contribute to the 
enhancement of mechanical performance of fibers (Gonzalez et al. 2014; Minus et al. 2009; Spitalsky et al. 2010). Thus both FTIR and XRD were used to indicate the structure change of gel-spun lignin/PVA fibers before/after the incorporation of GO.

FTIR spectra of PVA composite fibers in Fig. 5 together with XRD patterns (Fig. $\mathrm{S} 1$ in SI ) were used to calculate the constants $a$ and $b$ in Equation (7) for further confirmation of all of the percent crystallinity of composite PVA fibers (Table 2). Amorphous PVA is related to the C-O vibrational mode at $1094 \mathrm{~cm}^{-1}$, and PVA crystallinity affects the peak at $1144 \mathrm{~cm}^{-1}$ (Lu et al. 2017a). The value of the $A_{1144 / A_{854}}$ ratio is an index of fiber crystallinity. The crystallinity of PVA composite fibers (Table 2) approximately agreed with overall trends shown for the mechanical properties of fibers (Fig. 2). In detail, fibers with 5\% lignin were more crystalline than those containing 30\% lignin. Both 5\% and 30\% lignin fibers with GO showed higher or close crystallinity values in comparison with fibers without GO. This is due to that the presence of GO in the crystalline region promotes the formation of crystals, which will be demonstrated later in Fig. 6. The highest degree of crystallinity occurred at $0.05 \%$ $\mathrm{GO} / 5 \%$ lignin, however, the value slightly decreased when GO content was more than $0.05 \%$ in $5 \%$ lignin/PVA fibers. Fibers with $30 \%$ lignin and $0.2 \%$ GO were obviously more crystalline than those containing $0 / 0.05 \% \mathrm{GO} / 0.1 \% \mathrm{GO}$, which had a similar value of crystallinity. 

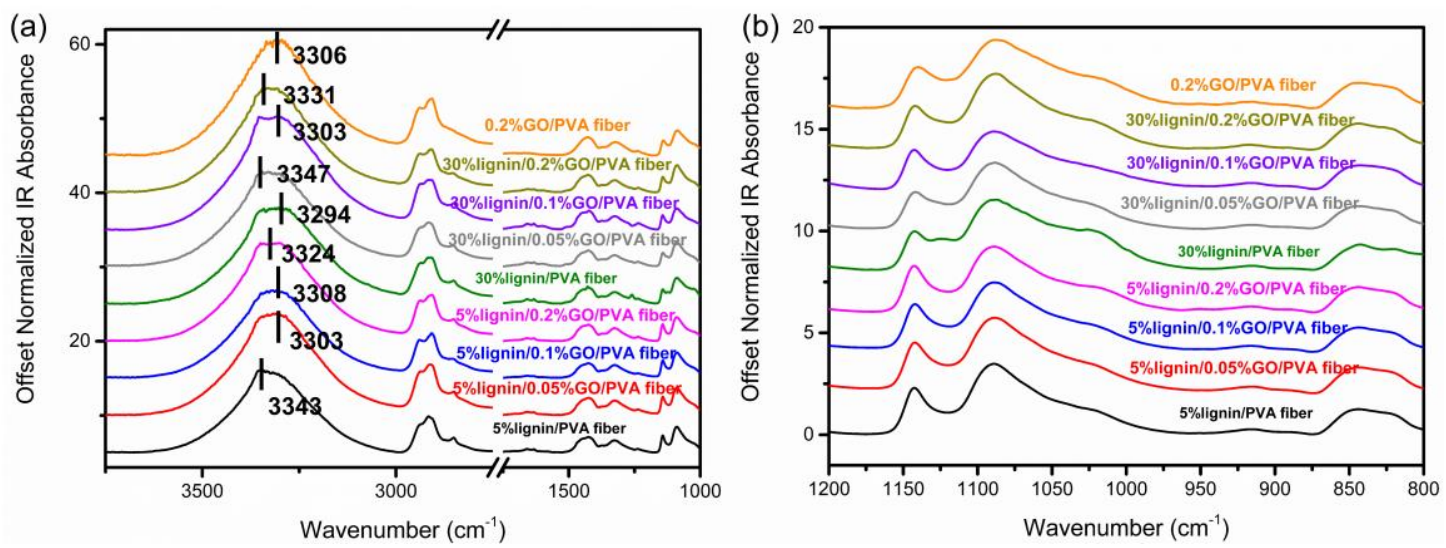

Fig. 5 FTIR absorbance spectra of gel-spun composite fibers between (a) 4200-1000

$\mathrm{cm}^{-1}$ and (b) $1250-800 \mathrm{~cm}^{-1}$

Table 2 FTIR absorbance ratios of $A_{1144 / A 854}$ and percent crystallinity $\left(X_{c}\right)$ of fibers

with different lignin and GO contents

\begin{tabular}{lcc}
\hline \multicolumn{1}{c}{ Sample } & $A_{1144} / A_{854}$ & $X_{c} / \%$ \\
\hline $0.2 \% \mathrm{GO} / \mathrm{PVA}$ & 1.91 & 51.78 \\
5\% lignin/PVA & 2.24 & 56.35 \\
0.05\% GO/5\% lignin/PVA & 2.44 & 59.70 \\
0.1\% GO/5\%lignin/PVA & 2.38 & 58.36 \\
0.2\% GO/5\%lignin/PVA & 2.29 & 56.40 \\
30\% lignin/PVA & 1.98 & 52.60 \\
0.05\% GO/30\% lignin/PVA & 1.97 & 52.46 \\
0.1\% GO/30\% lignin/PVA & 1.99 & 52.75 \\
$0.2 \% \mathrm{GO} / 30 \%$ lignin/PVA & 2.12 & 54.62 \\
\hline
\end{tabular}

Moreover, FTIR spectra implied the molecular interaction among GO, lignin and PVA. The peaks at $2942 \mathrm{~cm}^{-1}, 1440 \mathrm{~cm}^{-1}, 1086 \mathrm{~cm}^{-1}$, and $854 \mathrm{~cm}^{-1}$ were associated with the vibrations of $\mathrm{C}-\mathrm{H}$ stretching, $-\mathrm{CH}_{2}$ bending, $\mathrm{C}-\mathrm{O}-\mathrm{C}$ asymmetric stretching, and $\mathrm{C}-$ C stretching, respectively. It was obvious that in GO/PVA, lignin/PVA, and

356 GO/lignin/PVA composite fibers, no new absorbance peaks occurred with the incorporation of lignin or GO, suggesting that no new functional groups were formed. 
FTIR absorbance spectra from 3000 to $3700 \mathrm{~cm}^{-1}$ (Fig. 5a) provides insight into hydrogen bonding. The -OH stretching vibration peak of 5\% lignin/PVA fiber is at 3343 $\mathrm{cm}^{-1}$. With the addition of $0.05 \% \mathrm{GO}$, the peak shifted to lower frequencies, indicating shorter distances between oxygen atoms $(\mathrm{O} \cdots \mathrm{O})$ from different hydroxyl groups (Jiang et al. 2012). The shift was possibly the result of intermolecular hydrogen bonding formed among GO, lignin, and PVA (Kubo and Kadla 2003). With higher GO content, the $\mathrm{OH}$ group absorbance peak shifted slightly to the higher frequencies, which might be due to the dissociation of hydrogen bonding between PVA molecular chains. The $\mathrm{OH}$ stretching vibration peak of $30 \%$ lignin/PVA fiber was at $3294 \mathrm{~cm}^{-1}$, indicating that the hydrogen bonding between PVA and lignin was strong. With the incorporation of GO, the peak shifted to higher frequencies at different levels, indicating that no more hydrogen bonding formed. Strong molecular interactions among composite fibers indicated good compatibility among GO, lignin, and PVA. As a result, gel-spun 372 composite fibers showed no evidence of filler aggregation within the fiber microstructure (Fig. 4) and possessed good mechanical performance (Fig. 2). In addition to the percent crystallinity investigation of fibers, XRD patterns (Fig. orientation (Smith and Lemstra 1980). Taken both percent crystallinity and orientation into consideration, the former may be the main factor that differentiated the mechanical 
performance of the fabricated fibers in this work since the molecular orientation of the polymer chains was similar.

Table 3 Orientation $(y)$ of gel-spun composite fibers

\begin{tabular}{ll}
\hline \multicolumn{1}{c}{ Sample } & $y / \%$ \\
\hline $0.2 \% \mathrm{GO} / 0 \%$ lignin/PVA & 92.6 \\
$0 \% \mathrm{GO} / 5 \%$ lignin/PVA & 91.8 \\
$0.1 \% \mathrm{GO} / 5 \%$ lignin/PVA & 90.0 \\
$0.2 \% \mathrm{GO} / 5 \%$ lignin/PVA & 92.0 \\
\hline
\end{tabular}

The reinforcement mechanism of GO in lignin/PVA fibers

The microstructure models of spinning dopes and fibers are shown in Fig. 6 to better illustrate the structure of GO reinforced lignin/PVA fibers. The distribution of GO, lignin, and PVA in the homogenous spinning dope is random (Fig. 6a). Entanglements between the PVA macromolecular chains exist and hydrogen bonding can be formed among GO, lignin, and PVA since they all have oxygen-containing functional groups. After the gel-spun solid fiber is obtained, take 5\% lignin/PVA fiber as an example, both crystalline and amorphous regions exist in the fiber structure (Fig. 6b1). PVA molecular chains are highly aligned along the fiber axis and partially crystallized, which are indicated by percent crystallinity and orientation results in Tables 2 and 3. Intramolecular bonding of PVA can be replaced by intermolecular interaction between lignin and PVA, which reduces the entanglement between macromolecules and is beneficial to the formation of crystalline regions. However,

397 when the lignin increased to $30 \%$, the amorphous structure of excessive filler results in the decrease of fiber crystallinity. In addition, the aggregation (Fig. 6 $b_{2}$ ) of lignin may 
hinder the alignment of the PVA chains and cause a further decrease of the crystallinity. With the incorporation of a small amount of GO, hydrogen bonding is formed between GO/lignin, GO/PVA in addition to lignin/PVA. More crystalline areas are formed in GO reinforced lignin/PVA fibers in comparison with that of 5\% and 30\% lignin/PVA fibers (Fig. $6 c_{1}$ and $6 c_{2}$ ). No lignin aggregation was observed in the SEM images of GO reinforced 30\% lignin/PVA fiber (Fig. 4d), indicating that hydrogen bonding between GO/lignin, GO/PVA promotes the even distribution of lignin in the fiber structure and the formation of crystals. However, due to the plasticizing effect and amorphous structure of lignin, the crystallinity of GO reinforced 30\% lignin/PVA fiber is lower than that of GO reinforced 5\% lignin/PVA fiber (Table 2).

In summary, the enhancement of GO reinforced lignin/PVA fiber properties could be attributed to the following three reasons. First, GO has excellent inherent mechanical properties (tensile strength of $125 \mathrm{GPa}$ and Young's modulus of $1000 \mathrm{GPa}$ (McAllister et al. 2007). When the composite fiber is under tension, the load is effectively transferred from the polymer matrix to $\mathrm{GO}$, the mechanical properties of the fiber are therefore improved. Secondly, GO has good compatibility with PVA and lignin. Hydrogen bonding can be formed among them, which effectively avoids the aggregation of excessive lignin and the formation of fiber structure defects. Finally, the addition of GO favors the alignment of PVA molecular chains along the fiber axis, which is beneficial to the formation of crystalline regions (Table 2). 


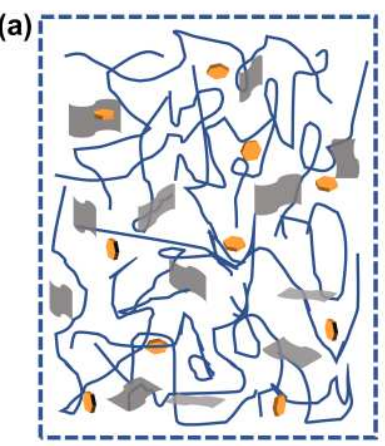

Crystalline region Amorphous region
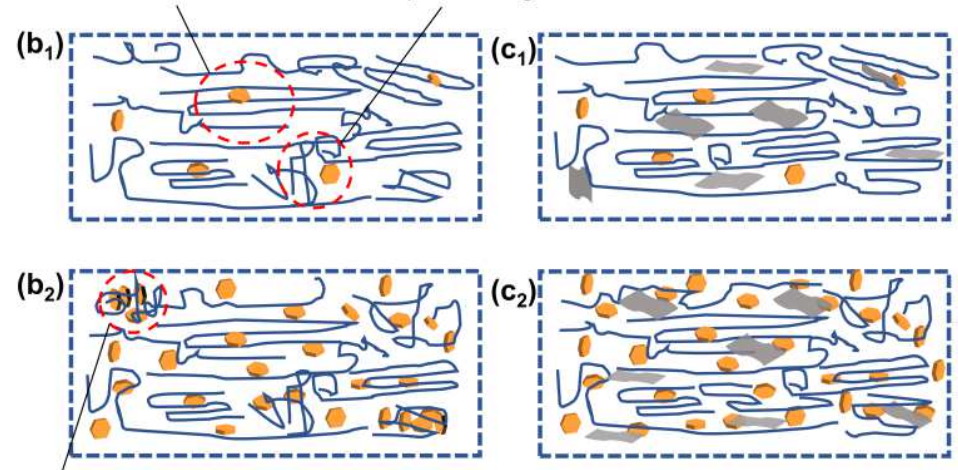

Lignin aggregation

Lignin

GO

Fig. 6. The microstructure model of (a) GO/lignin/PVA spinning dope and (1) 5\% (2)

$421 \quad 30 \%$ lignin/PVA fibers (b) without and (c) with GO

422 Water resistance of composite fibers

PVA fibers are susceptible to water at elevated temperatures due to their polar

424 chemical structure (Lu et al. 2017a). In this study, it was evidenced that lignin and GO behavior was observed at elevated temperatures. 
$\left(a_{1}\right)$

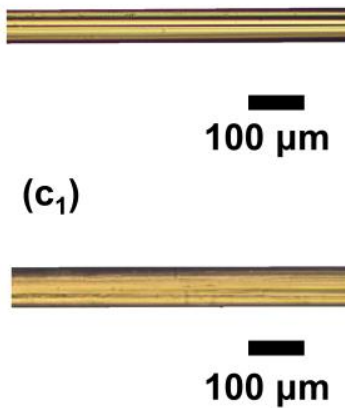

$\left(e_{1}\right)$
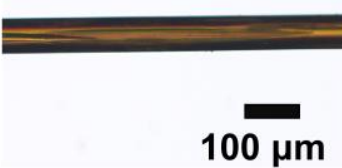

$\left(g_{1}\right)$

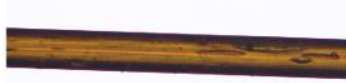

$100 \mu \mathrm{m}$ $\left(a_{2}\right)$

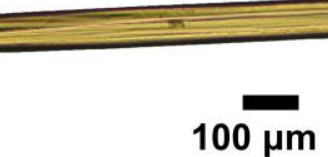

(c $\left.c_{2}\right)$

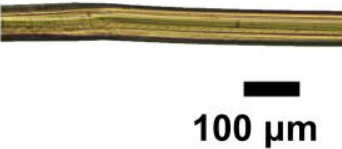

$\left(e_{2}\right)$

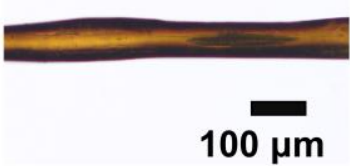

$\left(g_{2}\right)$

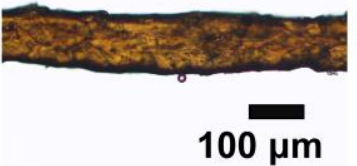

$\left(b_{1}\right)$
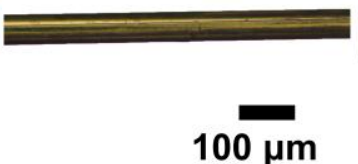

$\left(d_{1}\right)$

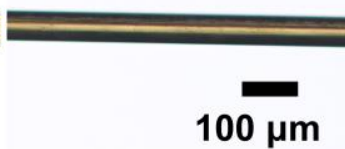

$\left(f_{1}\right)$

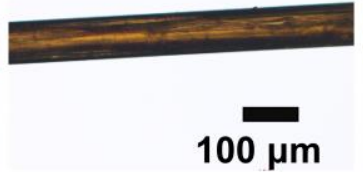

$\left(h_{1}\right)$

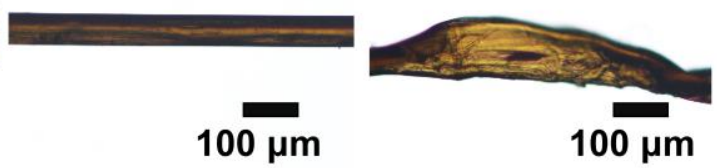

Fig. 7 Optical micrographs of (a) 5\% lignin/PVA fiber, (b) $0.05 \%$ GO/5\% lignin/PVA fiber, (c) $0.1 \% \mathrm{GO} / 5 \%$ lignin/PVA fiber, (d) $0.2 \% \mathrm{GO} / 5 \%$ lignin/PVA fiber, (e) $30 \%$ lignin/PVA fiber, (f) $0.05 \% \mathrm{GO} / 30 \%$ lignin/PVA fiber, (g) $0.1 \% \mathrm{GO} / 30 \%$ lignin/PVA fiber, (h) $0.2 \% \mathrm{GO} / 30 \%$ lignin/PVA fiber after water immersion at (1) $25{ }^{\circ} \mathrm{C}$ and (2) $85^{\circ} \mathrm{C}$

The dissolution of GO/PVA, lignin/PVA, and GO/lignin/PVA composite fibers were tested in water at different temperatures. Water resistance behavior of the composite fibers at room temperature and high temperature was observed by an optical microscope (Fig. 7). After being immersed in water at $25^{\circ} \mathrm{C}$, all fibers showed intact structures. Although pure PVA fibers are soluble in water at $85^{\circ} \mathrm{C}(\mathrm{Lu}$ et al. 2017a), the dissolution of PVA fibers in water at $85^{\circ} \mathrm{C}$ is hindered with the incorporation of lignin 
or GO due to the intermolecular hydrogen bonding among GO, lignin, and PVA. In detail, $0.2 \% \mathrm{GO} / \mathrm{PVA}$ fiber had an increase in diameter due to swelling in hot water at $85^{\circ} \mathrm{C}$, and it still maintained its intact fiber structure (Fig. S5, SI). At 5\% lignin, the GO/lignin/PVA fibers (Fig. 7a2-d2) exhibited increased diameter by swelling in water at $85^{\circ} \mathrm{C}$. At $30 \%$ lignin (Fig. 7 e 2 -h 2 ), the GO/lignin/PVA fibers immersed in water at $85{ }^{\circ} \mathrm{C}$ showed more significant swelling behavior and gel-like structure under the optical microscope. The possible explanation could be that PVA fibers with $30 \%$ lignin content had more amorphous region (lower crystallinity) than that of 5\% lignin/PVA fibers, thus the amorphous region in PVA fibers absorbed more water. Moreover, with GO content increased from 0 to $0.2 \%$, both $5 \%$ and $30 \%$ lignin/PVA fibers exhibited more obvious swollen structure, which was possibly attributed to that the hydrogen bonding formation of GO/lignin, GO/PVA and lignin/PVA promotes the structural network formation in the swollen fibers.

To further study the structural difference between fully drawn composite fibers, swelling ratio $(S)$ revealing moisture uptake capability of fibers at room temperature was measured and presented in Table 4. GO content had no significant influence on the moisture uptake of fibers with 5\% lignin and 30\% lignin. At the same GO content (i.e. $0.2 \%$ ), when lignin content increased from $0 \%$ to $30 \%$, the swelling ratio increased slightly from $5.13 \%$ to $6.67 \%$. This was due to that PVA fibers with $30 \%$ lignin were less crystalline so that the amorphous regions absorbed more water than PVA fibers with $0 \%$ and $5 \%$ lignin. The most crystalline $0.05 \% \mathrm{GO} / 5 \%$ lignin /PVA fiber exhibited a swelling ratio of $4.09 \%$, which was lower than other fibers. These results agree with 
the structural analysis of percent crystallinity shown in Table 2.

Table 4 Swelling ratios $(S)$ of gel-spun fibers after $24 \mathrm{~h}$ of water immersion.

\begin{tabular}{lccc}
\hline \multicolumn{1}{c}{ Fiber } & $S(\%)$ & \multicolumn{1}{c}{ Fiber } & $S(\%)$ \\
\hline $0.2 \% \mathrm{GO} / 0 \%$ lignin/PVA & 5.13 & $/$ & $/$ \\
$0 \% \mathrm{GO} / 5 \%$ lignin/PVA & 5.69 & $0 \% \mathrm{GO} / 30 \%$ lignin/PVA & 6.45 \\
$0.05 \% \mathrm{GO} / 5 \%$ lignin/PVA & 4.09 & $0.05 \% \mathrm{GO} / 30 \%$ lignin/PVA & 7.06 \\
$0.1 \% \mathrm{GO} / 5 \%$ lignin/PVA & 4.76 & $0.1 \% \mathrm{GO} / 30 \%$ lignin/PVA & 6.84 \\
$0.2 \% \mathrm{GO} / 5 \%$ lignin/PVA & 5.26 & $0.2 \% \mathrm{GO} / 30 \%$ lignin/PVA & 6.67 \\
\hline
\end{tabular}

\section{Conclusions}

We have successfully fabricated gel-spun bio-based GO/lignin/PVA fibers which demonstrate promising results of mechanical performance. With the incorporation of GO, the aggregation of fillers was avoided and enhancement in fiber mechanical properties was observed. With the GO content increasing from 0 to $0.2 \%$, the tensile strength of 5\% lignin/PVA fiber increased from $491 \mathrm{MPa}$ to $631 \mathrm{MPa}$, and Young's modulus increased from 5.91 GPa to $6.61 \mathrm{GPa}$. GO reinforced 30\% lignin/PVA fibers also exhibited the same increasing trend. The tensile strength increased from $455 \mathrm{MPa}$ to $553 \mathrm{MPa}$, and Young's modulus increased from 5.39 GPa to $7 \mathrm{GPa}$. Thus, GO favors the formation of defect-free fiber structure and the enhancement of fiber performance. The structural enhancement at $0.2 \% \mathrm{GO} / 5 \%$ lignin/PVA fiber was evidenced by its high crystallinity, intermolecular bonding among lignin, GO, and PVA, and good alignment of molecular chains. The good mechanical performance of gel-spun GO/lignin/PVA 


\section{Acknowledgments}

The authors are deeply grateful for the financial support received from the National Natural Science Foundation of China (Grant no. 51903033), Shanghai Sailing Program, China (Grant no. 19YF1400800), and Fundamental Research Funds for the Central Universities (Grant nos. 20D110110 and 2232020G-01).

\section{Author information}

\section{Affiliation:}

Key Laboratory of Textile Science \& Technology, Ministry of Education, College of Textiles, Donghua University, Shanghai 201620, China

*Correspondence author's email: chlu@dhu.edu.cn

\section{Compliance with ethical standards}

Conflict of interest The authors declare that they have no conflict of interest.

\section{References}

Baker DA, Rials TG (2013) Recent advances in low-cost carbon fiber manufacture from lignin. Journal of Applied Polymer Science 130:713-728 doi:10.1002/app.39273

Cha WI, Hyon SH, Ikada Y (1994) Gel spinning of poly(vinyl alcohol) from dimethyl sulfoxide/water mixture. Journal of Polymer Science Part B-Polymer Physics 32:297-304 doi:10.1002/polb.1994.090320211 
Gonzalez JS, Luduena LN, Ponce A, Alvarez VA (2014) Poly(vinyl alcohol)/cellulose nanowhiskers nanocomposite hydrogels for potential wound dressings. Materials Science \& Engineering C-Materials for Biological Applications 34:54-61 doi:10.1016/j.msec.2013.10.006

Hu M, Chen Z, Luo S, Yang X, Ye R, Zheng M, Chen P (2019) Preparation of graphene oxide and alkali lignin nanohybrids and its application to reinforcing polymer. Wood Science and Technology 53:649-664 doi:10.1007/s00226-019-01094-z

Hu TQ (2002) Chemical modification, properties, and usage of lignin. Springer, New York

Hu X et al. (2017) Highly aligned graphene oxide/poly(vinyl alcohol) nanocomposite fibers with high-strength, antiultraviolet and antibacterial properties. Composites Part A: Applied Science and Manufacturing 102:297-304 doi:10.1016/j.compositesa.2017.08.015

Iwaseya M, Watanabe M, Yamaura K, Dai LX, Noguchi H (2005) High performance films obtained from PVA/ $\mathrm{Na}_{2} \mathrm{SO}_{4} / \mathrm{H}_{2} \mathrm{O}$ and $\mathrm{PVA} / \mathrm{CH}_{3} \mathrm{COONa} / \mathrm{H}_{2} \mathrm{O}$ systems. Journal of Materials Science 40:5695-5698 doi:10.1007/s10853-005-1429-6

Jiang X, Tan B, Zhang X, Ye D, Dai H, Zhang X (2012) Studies on the properties of poly(vinyl alcohol) film plasticized by urea/ethanolamine mixture. Journal of Applied Polymer Science 125:697-703 doi:10.1002/app.34957

Kaufmann J, Hesselbarth D (2007) High performance composites in spun-cast elements. Cement \& Concrete Composites 29:713-722 doi:10.1016/j.cemconcomp.2007.06.001

Kubo S, Kadla JF (2003) The formation of strong intermolecular interactions in immiscible blends of poly(vinyl alcohol) (PVA) and lignin. Biomacromolecules 4:561-567 doi:10.1021/bm025727p 
Kubo S, Kadla JF (2005) Lignin-based carbon fibers: effect of synthetic polymer blending on fiber properties. Journal of Polymers and the Environment 13:97-105 doi:10.1007/s10924005-2941-0

Laurichesse S, Avérous L (2014) Chemical modification of lignins: towards biobased polymers. Progress in Polymer Science 39:1266-1290 doi:10.1016/j.progpolymsci.2013.11.004

Lee C, Wei X, Kysar JW, Hone J (2008) Measurement of the elastic properties and intrinsic strength of monolayer graphene. Science 321:385-388 doi:10.1126/science.1157996

Liang J, Huang Y, Zhang L, Wang Y, Ma Y, Guo T, Chen Y (2009) Molecular-Level Dispersion of Graphene into Poly(vinyl alcohol) and Effective Reinforcement of their Nanocomposites. Advanced $\quad$ Functional 19:2297-2302 doi:10.1002/adfm.200801776

Liu HC, Chien A-T, Newcomb BA, Liu Y, Kumar S (2015) Processing, structure, and properties of lignin- and CNT-incorporated polyacrylonitrile-based carbon fibers. ACS Sustainable Chemistry \& Engineering 3:1943-1954 doi:10.1021/acssuschemeng.5b00562

Lu C, Blackwell C, Ren Q, Ford E (2017a) Effect of the coagulation bath on the structure and mechanical properties of gel-spun lignin/poly(vinyl alcohol) fibers. ACS Sustainable Chemistry \& Engineering 5:2949-2959 doi:10.1021/acssuschemeng.6b02423

Lu C, Ford E (2018) Antiplasticizing behaviors of glucarate and lignin bio-based derivatives on the properties of gel-spun poly(vinyl alcohol) fibers. Macromolecular Materials and Engineering 303 doi:10.1002/mame.201700523

Lu C, Rawat P, Louder N, Ford E (2017b) Properties and structural anisotropy of gel-spun lignin/poly(vinyl alcohol) fibers due to gel aging. ACS Sustainable Chemistry \& 
Luo J, Li Q, Zhao T, Gao S, Sun S (2013) Bonding and toughness properties of PVA fibre reinforced aqueous epoxy resin cement repair mortar. Construction and Building Materials 49:766-771 doi:10.1016/j.conbuildmat.2013.08.052

551

552

Luo Q, Shan Y, Zuo X, Liu J (2018) Anisotropic tough poly(vinyl alcohol)/graphene oxide nanocomposite hydrogels for potential biomedical applications. RSC Advances 8:1328413291 doi:10.1039/c8ra00340h

McAllister MJ et al. (2007) Single sheet functionalized graphene by oxidation and thermal expansion of graphite. Chemistry of Materials 19:4396-4404 doi:10.1021/cm0630800

Minus ML, Chae HG, Kumar S (2006) Single wall carbon nanotube templated oriented $\begin{array}{llll}\text { crystallization } & \text { of } & \text { poly(vinyl alcohol). } & \text { Polymer }\end{array}$ doi:10.1016/j.polymer.2006.03.076

Minus ML, Chae HG, Kumar S (2009) Interfacial crystallization in gel-spun poly(vinyl alcohol)/single-wall carbon nanotube composite fibers. Macromolecular Chemistry and Physics 210:1799-1808 doi:10.1002/macp.200900223

Peppas NA (1977) Infrared spectroscopy of semicrystalline poly(vinyl alcohol) networks. Macromolecular Chemistry and Physics 178:596-601

Rourke JP, Pandey PA, Moore JJ, Bates M, Kinloch IA, Young RJ, Wilson NR (2011) The real graphene oxide revealed: stripping the oxidative debris from the graphene-like sheets. Angew Chem Int Ed Engl 50:3173-3177 doi:10.1002/anie.201007520

Shin MK et al. (2012) Synergistic toughening of composite fibres by self-alignment of reduced graphene oxide and carbon nanotubes. Nature Communications 3:650 
Smith P, Lemstra PJ (1980) Ultra-high-strength polyethylene filaments by solution spinning/drawing. Journal of Materials Science 15:505-514

Song P, Xu Z, Guo Q (2013) Bioinspired strategy to reinforce PVA with improved toughness doi:10.1021/mz4005265

Spitalsky Z, Tasis D, Papagelis K, Galiotis C (2010) Carbon nanotube-polymer composites: Chemistry, processing, mechanical and electrical properties. Progress in Polymer Science 35:357-401 doi:10.1016/j.progpolymsci.2009.09.003

Sudo K, Shimizu K (1992) A new carbon fiber from lignin. Journal of Applied Polymer Science $44: 127-134$

Sun W, Chen HS, Luo X, Qian HP (2001) The effect of hybrid fibers and expansive agent on the shrinkage and permeability of high-performance concrete. Cement and Concrete Research 31:595-601 doi:10.1016/s0008-8846(00)00479-8

Thakur VK, Thakur MK, Raghavan P, Kessler MR (2014) Progress in green polymer composites from lignin for multifunctional applications: a review. ACS Sustainable Chemistry \& Engineering 2:1072-1092 doi:10.1021/sc500087z

Tretinnikov ON, Zagorskaya SA (2012) Determination of the degree of crystallinity of poly(vinyl alcohol) by FTIR spectroscopy. Journal of Applied Spectroscopy 79:521-526

Uddin AJ, Araki J, Gotoh Y (2011) Toward "strong" green nanocomposites: polyvinyl alcohol reinforced with extremely oriented cellulose whiskers. Biomacromolecules 12:617-624 doi:10.1021/bm101280f 
591 Wilson NR et al. (2009) Graphene oxide: structural analysis and application as a highly 592 transparent support for electron microscopy. ACS Nano 3:2547-2556

593 Xu X, Uddin AJ, Aoki K, Gotoh Y, Saito T, Yumura M (2010) Fabrication of high strength PVA/SWCNT composite fibers by gel spinning. Carbon 48:1977-1984 doi:10.1016/j.carbon.2010.02.004

Zhang W, Zhu Y, Zhu X, Zhang J, Huang X, Fu J (2011) Study on high strength PVA fiber produced by DMSO method. Synthetic Technology and Application 26:7-11

Zhu Y, Cao Q, Chen X, Zha L (2009) Crystallite orientation and spiral structure of cotton:part

Zhu Y, Murali S, Cai W, Li X, Suk JW, Potts JR, Ruoff RS (2010) Graphene and graphene oxide:

601 synthesis, properties, and applications. Advanced Materials 22:3906-3924

602 doi:10.1002/adma.201001068

603 
(a)

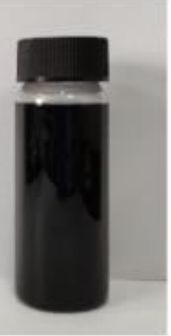

(b)

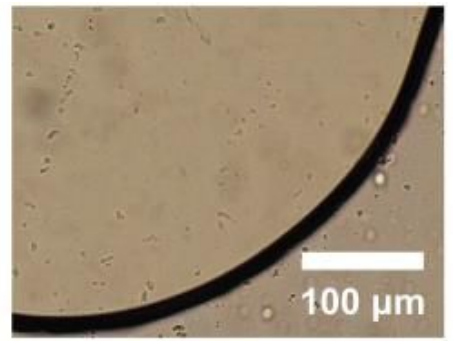

(c)

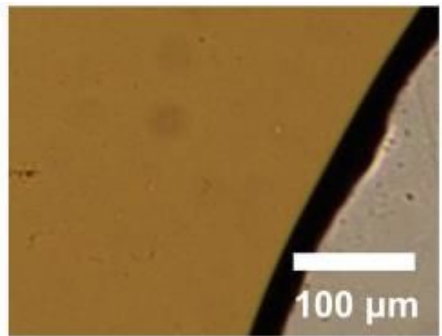

(d)

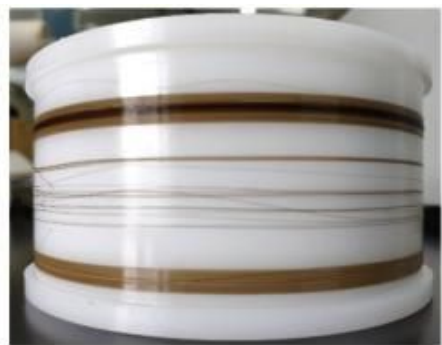

(e) Pressure

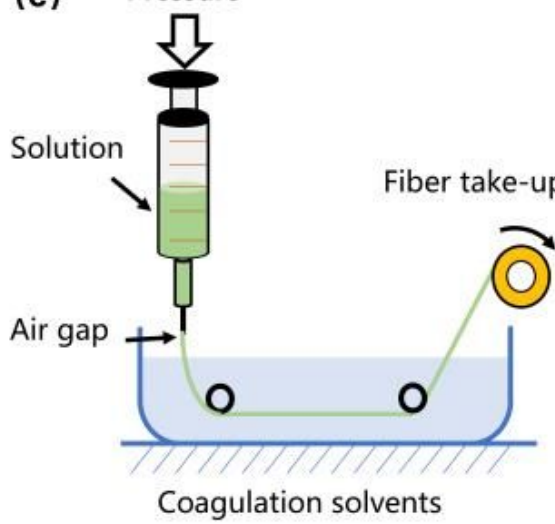

Step 1 As-spun fiber

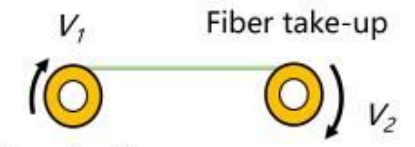

Fiber feeding

Step 2 Air drawing , $V_{2}>V_{1}$

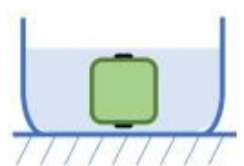

Coagulation solvents

Step 3 Aged gel fiber
Fiber feeding

Fiber take-up

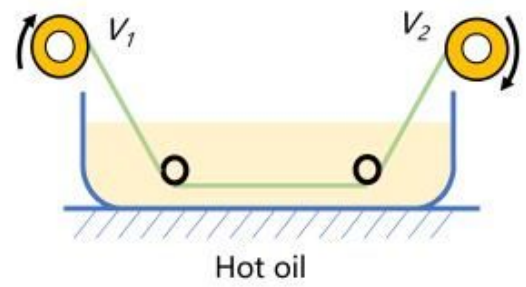

Step 4 Multi-stage drawing at elevated temperature, $V_{2}>V_{1}$

\section{Figure 1}

Homogeneity of GO/lignin/PVA dopes: (a) digital photograph of $0.2 \% \mathrm{GO} / 30 \%$ lignin/PVA solution, and optical micrographs of (b) $0.2 \% \mathrm{GO} / 5 \%$ lignin/PVA and (c) $0.2 \% \mathrm{GO} / 30 \%$ lignin/PVA spinning solutions; (d) digital photograph of 30\% lignin/PVA drawn fibers prepared by gel spinning, (e) the fiber gel spinning process: as-spun gel fiber formation (Step 1), air drawing (Step 2), gel fiber aging (Step 3), and multiplestage fiber drawing (Step 4)
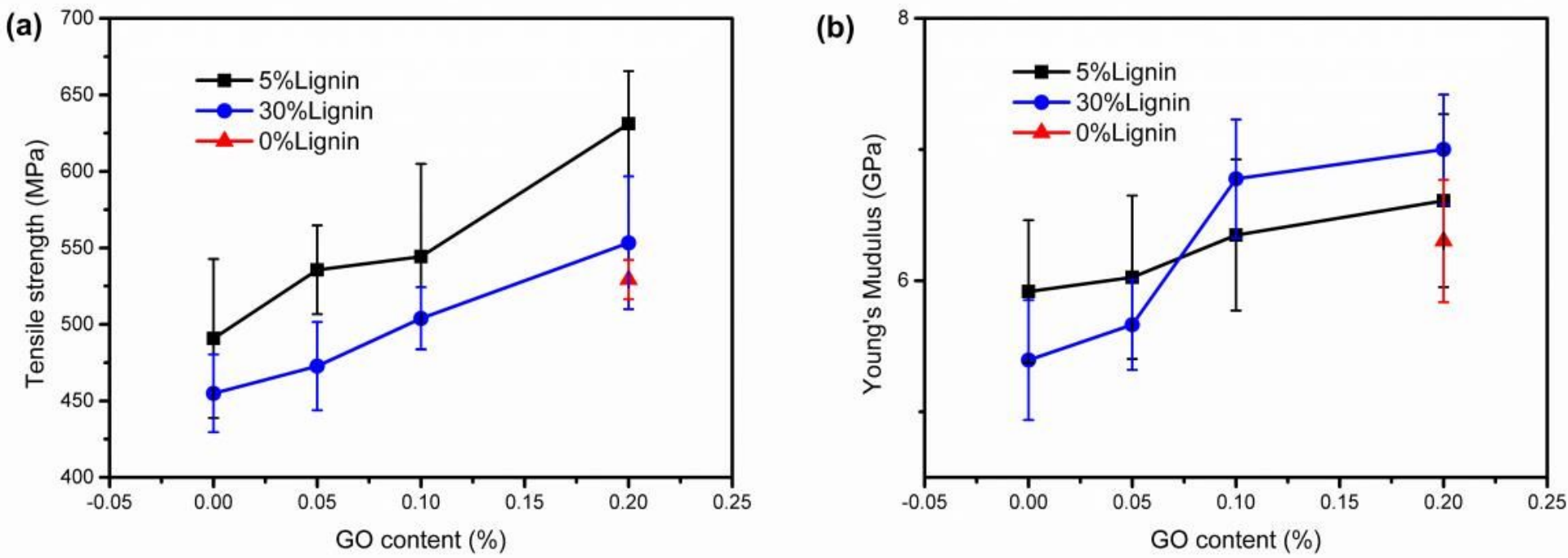

Figure 2 
Tensile strength and Young's modulus of gel-spun PVA fibers of $0 / 5 / 30 \%$ lignin and $0 / 0.05 \% / 0.1 \% / 0.2 \%$ GO

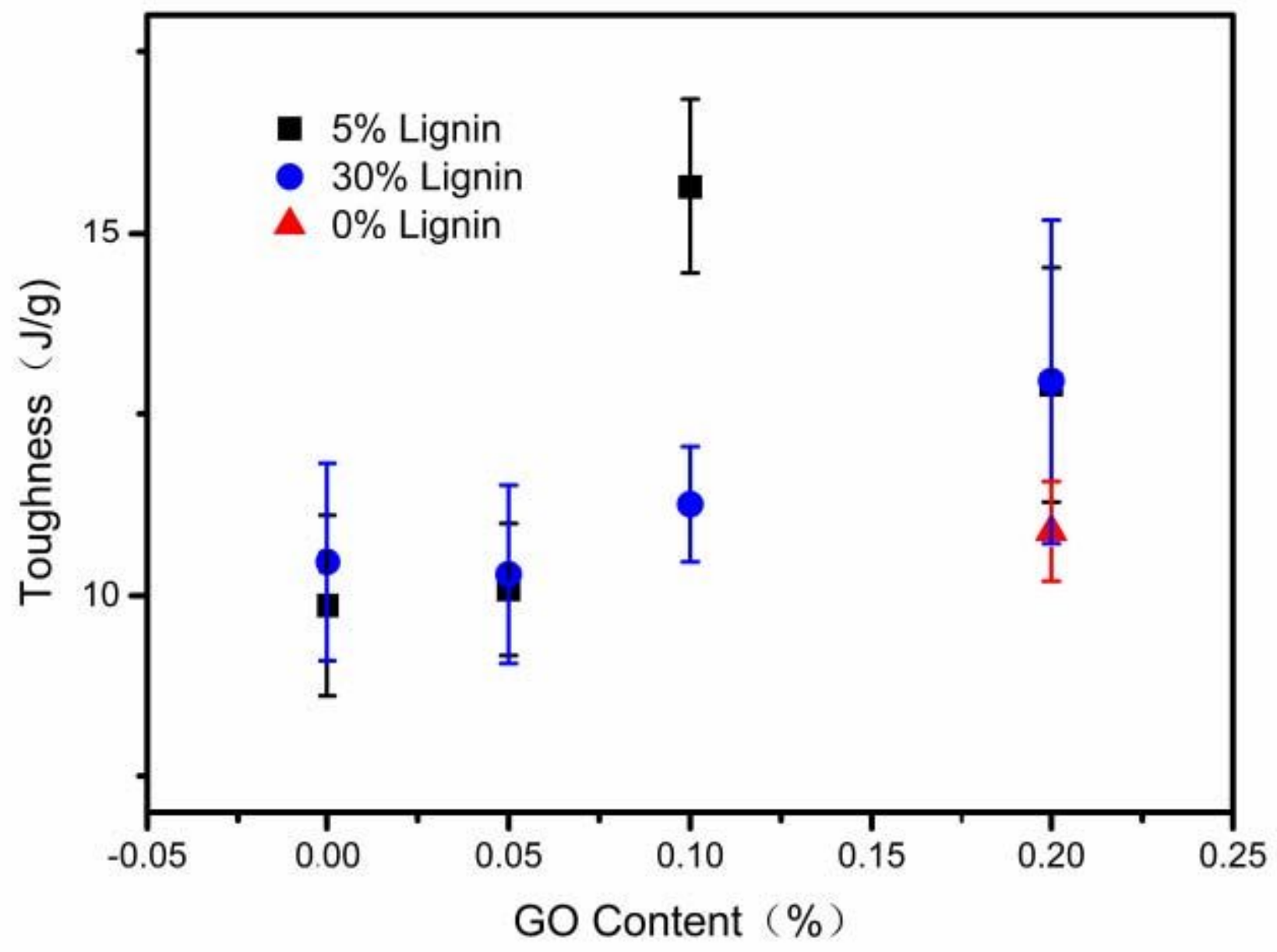

Figure 3

Toughness of gel-spun PVA fibers with $0 / 5 / 30 \%$ lignin and 0/0.05\%/0.1\%/0.2\% GO 

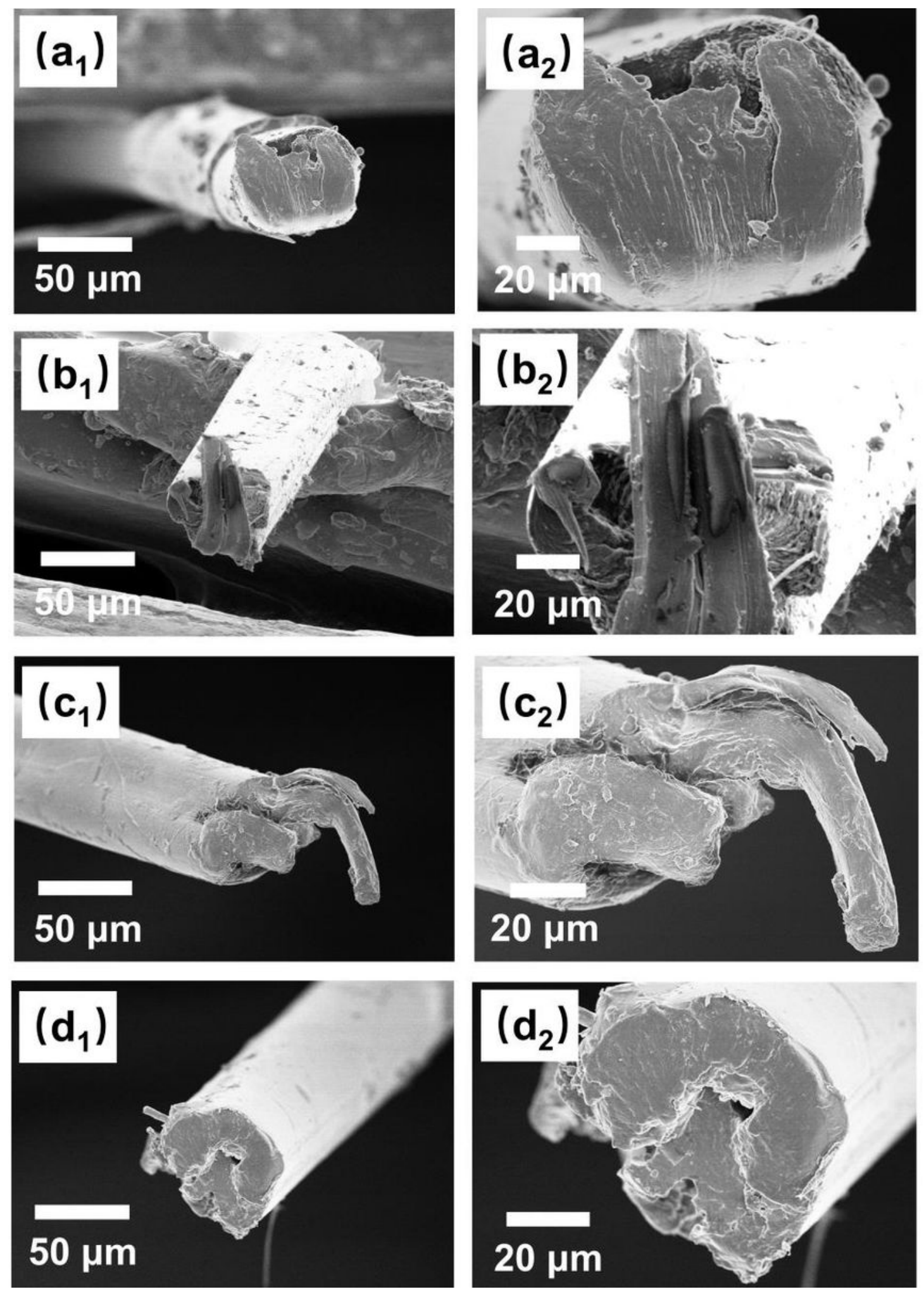

Figure 4

(1) Low- and (2) high-resolution SEM images of fracture tips of (a) $5 \%$ lignin /PVA fibers, (b) $0.2 \%$ GO/5\% lignin/PVA fibers, (c) $30 \%$ lignin/PVA fibers, (d) $0.2 \%$ Go/30\% lignin/PVA fibers 

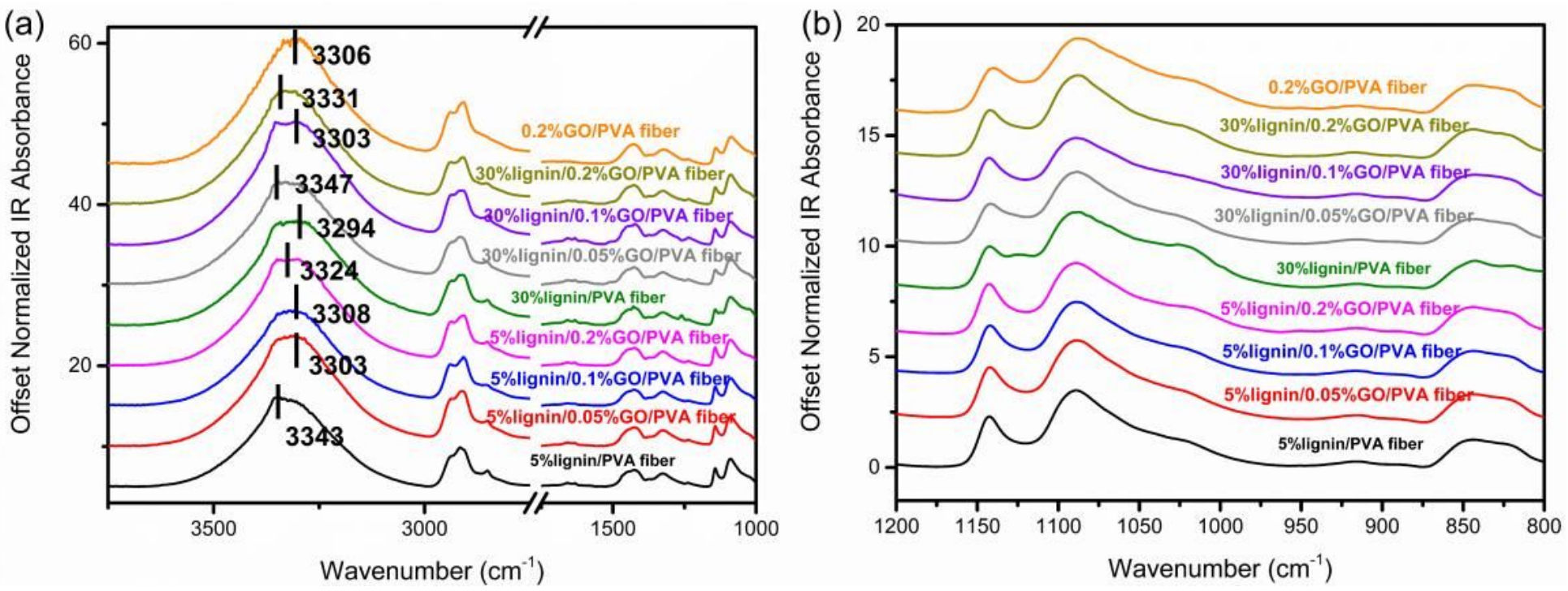

Figure 5

FTIR absorbance spectra of gel-spun composite fibers between (a) 4200-1000 cm-1 and (b) 1250-800 $\mathrm{cm}-1$

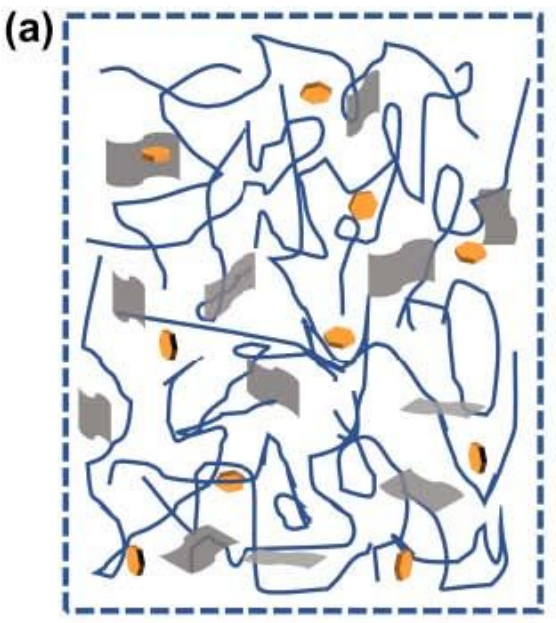

\section{Crystalline region Amorphous region}
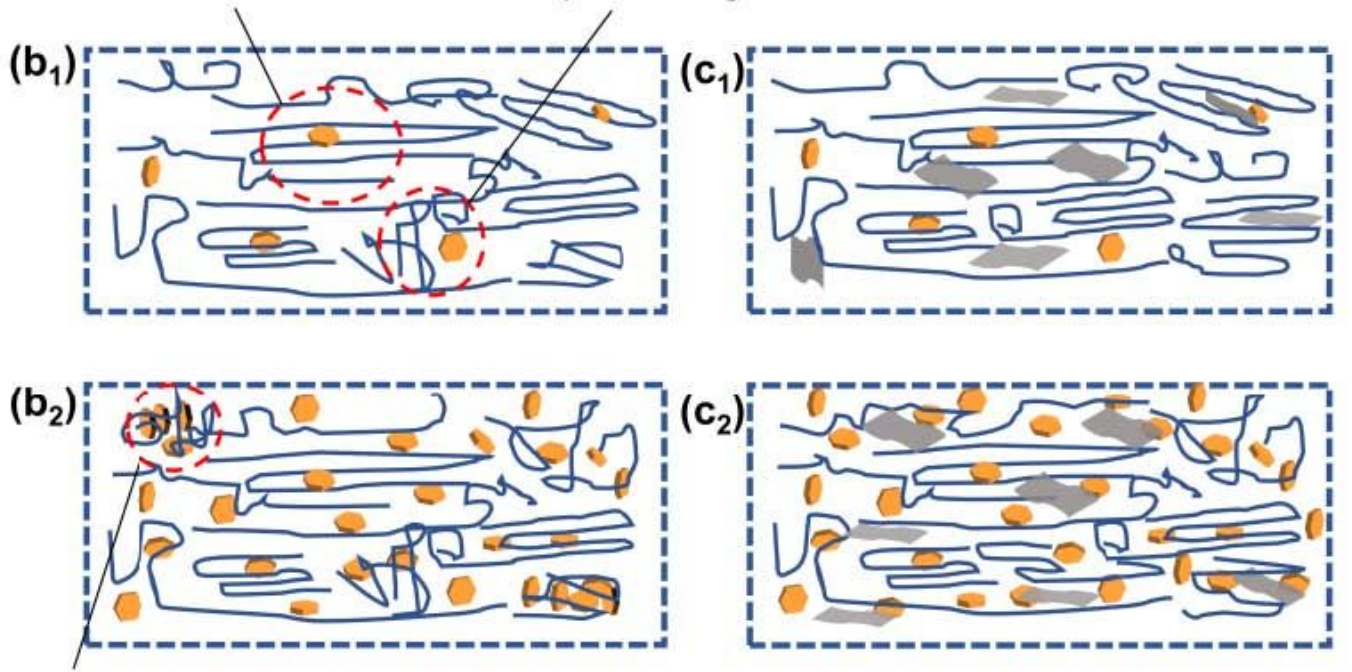

Lignin aggregation

PVA chains $\rightarrow$ Lignin GO

Figure 6

The microstructure model of (a) Go/lignin/PVA spinning dope and (1) 5\% (2) 30\% lignin/PVA fibers (b) without and (c) with GO 
$\left(a_{1}\right)$

$\left(a_{2}\right)$

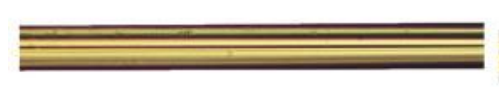

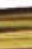

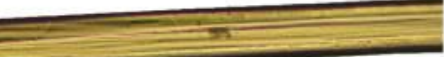

(b $\left.b_{1}\right)$

$\left(b_{2}\right)$

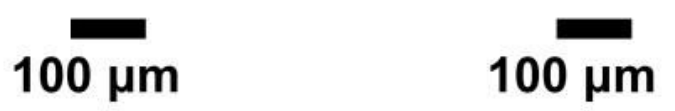

(c)

$\left(c_{2}\right)$

$\left(d_{1}\right)$

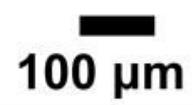

$\left(d_{2}\right)$
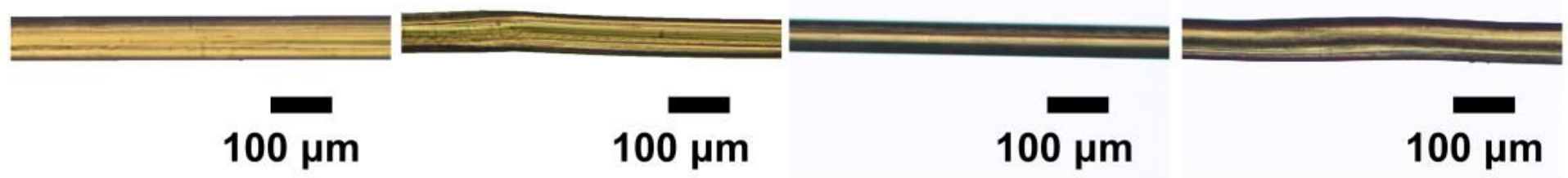

$\left(e_{1}\right)$

$\left(e_{2}\right)$

$\left(f_{1}\right)$

$\left(f_{2}\right)$
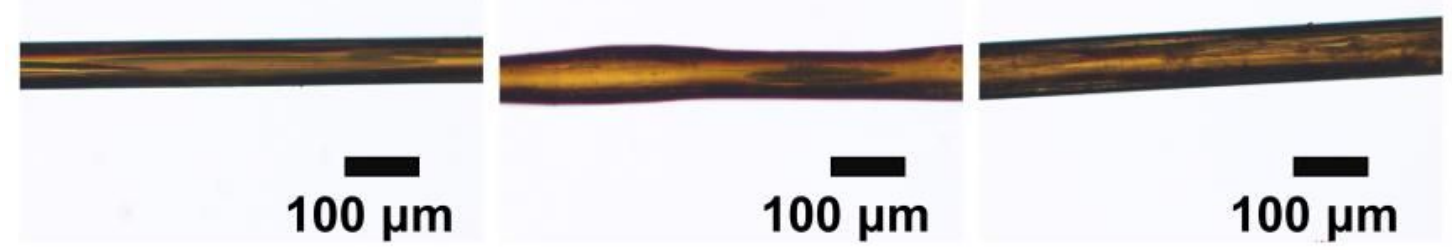

$\left(g_{1}\right)$

$\left(g_{2}\right)$

$\left(h_{1}\right)$
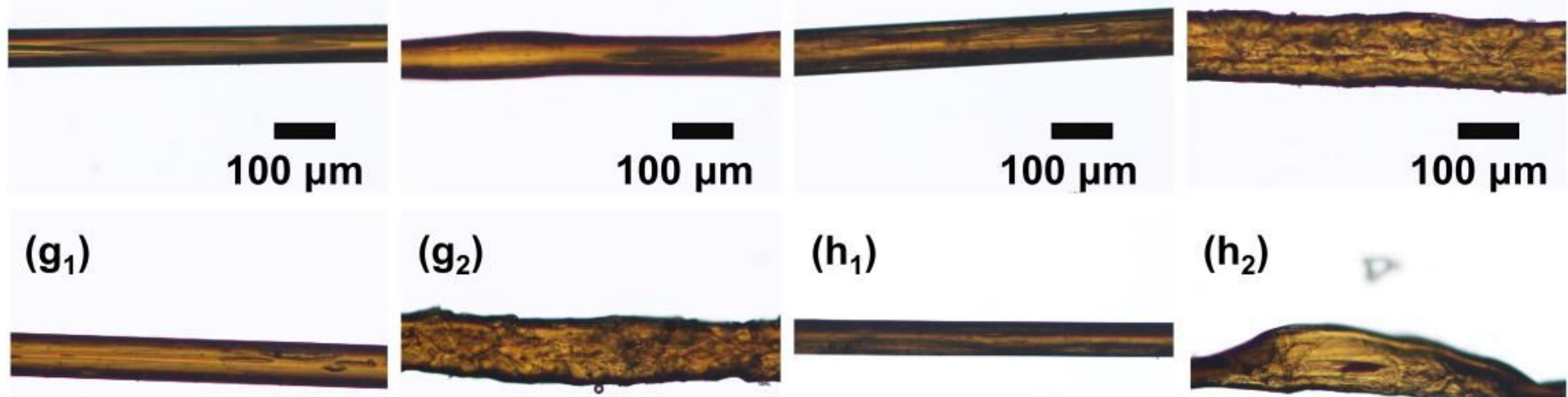

$100 \mu \mathrm{m}$
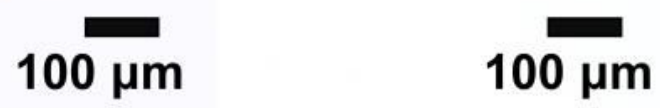

$\left(h_{2}\right)$

Figure 7

Optical micrographs of (a) $5 \%$ lignin/PVA fiber, (b) $0.05 \%$ GO/5\% lignin/PVA fiber, (c) $0.1 \%$ GO/5\% lignin/PVA fiber, (d) $0.2 \%$ GO/5\% lignin/PVA fiber, (e) 30\% lignin/PVA fiber, (f) $0.05 \%$ Go/30\% lignin/PVA fiber, (g) $0.1 \% \mathrm{GO} / 30 \%$ lignin/PVA fiber, (h) $0.2 \% \mathrm{GO} / 30 \%$ lignin/PVA fiber after water immersion at (1) 25 ${ }^{\circ} \mathrm{C}$ and $(2) 85^{\circ} \mathrm{C}$

\section{Supplementary Files}

This is a list of supplementary files associated with this preprint. Click to download.

- SupplementaryInformation.docx

- GraphicalAbstract.jpg 